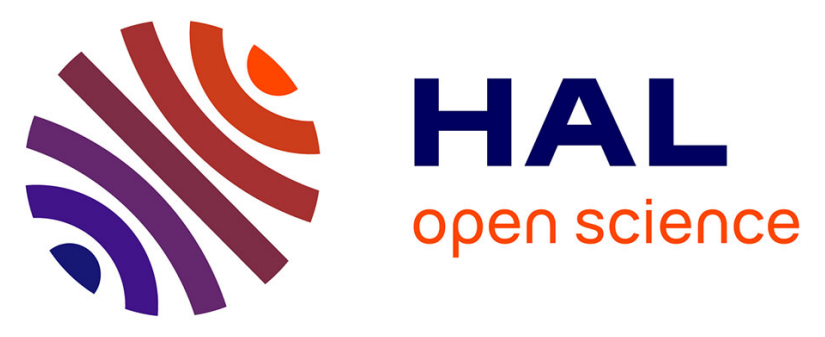

\title{
Substitution Effects in Highly Syndioselective Styrene Polymerization Catalysts Based on Single-Component Allyl ansa-Lanthanidocenes: An Experimental and Theoretical Study
}

Eva Laur, Elisa Louyriac, Vincent Dorcet, Alexandre Welle, Aurélien Vantomme, Olivier Miserque, Jean-Michel Brusson, Laurent Maron, Jean-François Carpentier, Evgueni Kirillov

\section{- To cite this version:}

Eva Laur, Elisa Louyriac, Vincent Dorcet, Alexandre Welle, Aurélien Vantomme, et al.. Substitution Effects in Highly Syndioselective Styrene Polymerization Catalysts Based on Single-Component Allyl ansa-Lanthanidocenes: An Experimental and Theoretical Study. Macromolecules, 2017, 50 (17), pp.6539-6551. 10.1021/acs.macromol.7b00853 . hal-01614773

HAL Id: hal-01614773

https://hal-univ-rennes1.archives-ouvertes.fr/hal-01614773

Submitted on 13 Nov 2017

HAL is a multi-disciplinary open access archive for the deposit and dissemination of scientific research documents, whether they are published or not. The documents may come from teaching and research institutions in France or abroad, or from public or private research centers.
L'archive ouverte pluridisciplinaire HAL, est destinée au dépôt et à la diffusion de documents scientifiques de niveau recherche, publiés ou non, émanant des établissements d'enseignement et de recherche français ou étrangers, des laboratoires publics ou privés. 


\section{Substitution Effects in Highly Syndioselective Styrene Polymerization Catalysts Based on Single-Component Allyl ansa-Lanthanidocenes:}

\section{An Experimental and Theoretical Study}

Eva Laur, ${ }^{\mathrm{a}, \S}$ Elisa Louyriac,,${ }^{\mathrm{b}}{ }^{\S}$ Vincent Dorcet, ${ }^{\mathrm{a}}$ Alexandre Welle, ${ }^{\mathrm{c}}$ Aurélien Vantomme, ${ }^{\mathrm{c}}$ Olivier Miserque, ${ }^{\mathrm{c}}$ Jean-Michel Brusson, ${ }^{\mathrm{d}}$ Laurent Maron,,${ }^{\mathrm{b}}{ }^{*}$ Jean-François Carpentier, ${ }^{\mathrm{a},}{ }^{*}$ Evgueni Kirillov, ${ }^{\mathrm{a}}$,

${ }^{\text {a }}$ Université de Rennes 1, CNRS, Institut des Sciences Chimiques de Rennes, UMR 6226, F35042 Rennes Cedex, France

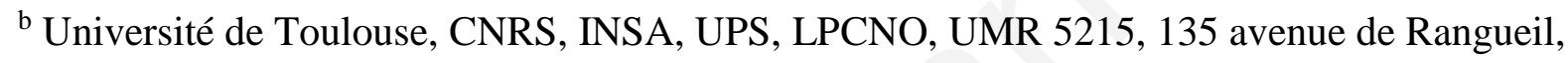
F-31077 Toulouse Cedex 4, France

${ }^{\mathrm{c}}$ Total Research \& Technology Feluy, Zone Industrielle C, B-7181 Feluy, Belgium

d Total S.A., Direction R\&D Groupe, 24 Cours Michelet, F-92069 Paris La Défense Cedex, France

\section{Graphical Abstract}

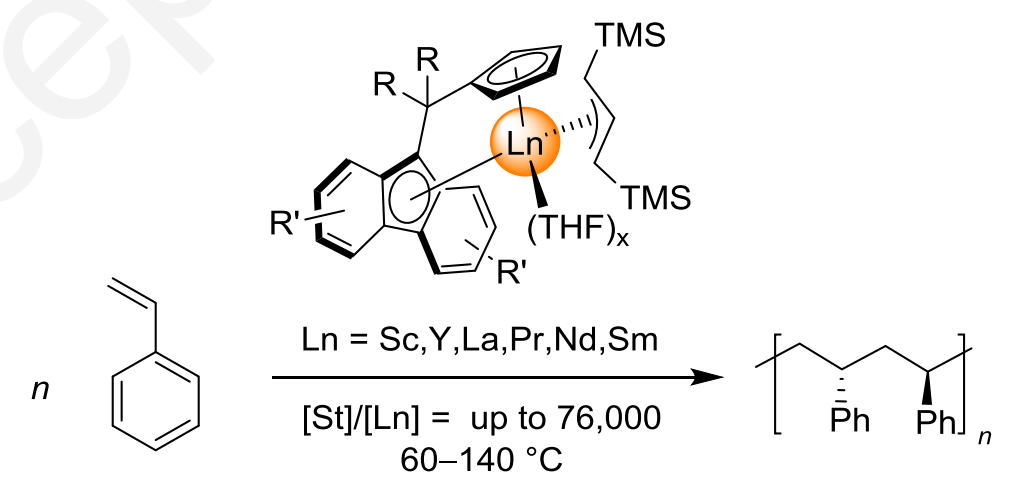

\footnotetext{
$\S$ Those two authors contributed equally to the manuscript, respectively for the experimental and theoretical parts.

*Corresponding authors: laurent.maron@irsamc.ups-tlse.fr; jean-francois.carpentier@univ-rennes1.fr (ORCID: 0000-0002-9160-7662); evgueni.kirillov@univ-rennes1.fr (ORCID: 0000-0002-5067-480X)
} 


\section{Abstract}

A series of allyl ansa-lanthanidocenes, $\left[\left\{\mathrm{Me}_{2} \mathrm{C}\left(\mathrm{C}_{5} \mathrm{H}_{4}\right)(\mathrm{Flu})\right\} \mathrm{Nd}\left(1,3-\mathrm{C}_{3} \mathrm{H}_{3}\left(\mathrm{SiMe}_{3}\right)_{2}\right)_{2}\right] \mathrm{K}(\mathrm{Flu}=$ 9-fluorenyl; 1-Nd-K(allyl)) and $\left\{\mathrm{R}_{2} \mathrm{C}\left(\mathrm{C}_{5} \mathrm{H}_{4}\right)\left(\mathrm{R}^{\prime} \mathrm{R}{ }^{\prime} \mathrm{Flu}\right)\right\} \mathrm{Ln}\left(1,3-\mathrm{C}_{3} \mathrm{H}_{3}\left(\mathrm{SiMe}_{3}\right)_{2}\right)(\mathrm{THF})_{x}(\mathrm{R}=$ $\mathrm{Me}, \mathrm{R}^{\prime}=2,7-t \mathrm{Bu}_{2}, \mathrm{Ln}=\mathrm{Y}(\mathbf{2}-\mathrm{Y}), \mathrm{Sc}(\mathbf{2 - S c}), x=0 ; \mathrm{Ln}=\mathrm{La}(\mathbf{2}-\mathbf{L a}), \operatorname{Pr}(\mathbf{2}-\mathrm{Pr}), \mathrm{Nd}(\mathbf{2}-\mathrm{Nd}), \mathrm{Sm}$ (2-Sm),$x=1 ; \mathrm{R}=\mathrm{Me}, \mathrm{R}^{\prime}=$ oct $=$ octamethyloctahydrodibenzo, $\mathrm{Ln}=\mathrm{Nd}, x=1(3-\mathrm{Nd}) ; \mathrm{R}=$ $\left.\mathrm{Ph}, \mathrm{R}^{\prime}=\mathrm{H}, \mathrm{Ln}=\mathrm{Nd}, x=1(\mathbf{4 - N d}) ; \mathrm{R}=\mathrm{Me}, \mathrm{R}^{\prime}=3,6-t \mathrm{Bu}_{2}, \mathrm{Ln}=\mathrm{Nd}, x=1(\mathbf{5}-\mathrm{Nd})\right)$, were prepared in good yields and characterized by NMR spectroscopy (for diamagnetic complexes 2-Sc, 2-Y and 2-La) and by single-crystal X-ray diffraction (1-Nd-K(allyl), 2-La, 2-Pr, 2Nd, 2-Sm and 4-Nd). Those complexes, especially 1-Nd-K(allyl), 2-Nd, 4-Nd, 2-La and 2$\mathbf{S m}$, act as single-component catalyst precursors for polymerization of styrene (in bulk or in aliphatic hydrocarbon solutions, $(n \mathrm{Bu})_{2} \mathrm{Mg}$ as scavenger, $\left.T_{\text {polym }}=60-140{ }^{\circ} \mathrm{C}\right)$, affording highly syndiotactic polystyrene (sPS) $\left([r]^{5}=63-88 \% ; T_{\mathrm{m}}\right.$ up to $\left.260{ }^{\circ} \mathrm{C}\right)$. High productivities (up to $4,560 \mathrm{~kg}(\mathrm{sPS}) \cdot \operatorname{mol}(\mathrm{Ln})^{-1} \cdot \mathrm{h}^{-1}$ ) were achieved at $120-140{ }^{\circ} \mathrm{C}$, at low catalyst loadings $([\mathrm{St}] /[\mathrm{Nd}]=20,000-76,000$ equiv), with 2-Nd and 2-Pr. On the other hand, precursors having bulky substituents on the fluorenyl moieties in 3,6- positions (3-Nd, 5-Nd) or based on small ionic radius metals (2-Y, $\mathbf{2}-\mathbf{S c})$ were poorly or not active under standard polymerization conditions. These results have been rationalized by DFT computations, which included the solvent, carried out on the putative 1-Nd, and the isolated 2-Nd and 5-Nd complexes. Three consecutive styrene insertions were studied and it was revealed that (i) the formation of sPS is thermodynamically controlled by two effects: minimization of repulsions between fluorenyl/styrene phenyl ring and (in the initiation phase) fluorenyl/SiMe 3 substituents of the allyl ligand, and (ii) the presence of bulky substituents on the fluorenyl moiety does not influence the activation barrier of monomer insertion, but it may destabilize thermodynamically the insertion product. 


\section{Introduction}

Since its discovery by Ishihara in $1985,{ }^{1}$ syndiotactic polystyrene (sPS) has attracted considerable interest over the past three decades. Several catalytic systems are now known as very effective in highly syndioselective styrene polymerization. A wide variety of alkoxy, cyclopentadienyl and indenyl titanium complexes, to be activated by MAO, have been developed. $2,3,4,5,6,7$ Besides, the independent discovery of the first neutral rare-earth metal complex $\left\{\mathrm{Me}_{2} \mathrm{C}\left(\mathrm{C}_{5} \mathrm{H}_{4}\right)(\mathrm{Flu})\right\} \mathrm{Nd}\left(\eta^{3}-\mathrm{C}_{3} \mathrm{H}_{5}\right)(\mathrm{THF})$ (I) (Flu = 9-fluorenyl), which acts as a single-component catalyst, ${ }^{8,9,10,11}$ and the first cationic rare-earth metal catalytic system $\left(\mathrm{C}_{5} \mathrm{Me}_{4} \mathrm{SiMe}_{3}\right) \mathrm{Sc}\left(\mathrm{CH}_{2} \mathrm{SiMe}_{3}\right)_{2}(\mathrm{THF}) /\left[\mathrm{Ph}_{3} \mathrm{C}\right]\left[\mathrm{B}\left(\mathrm{C}_{6} \mathrm{~F}_{5}\right)_{4}\right] \quad(\mathbf{I I})^{12}$ for $\quad$ syndiospecific polymerization of styrene, has led to the subsequent description of a large range of related rare-earth based competent catalyst systems. ${ }^{13,14,15,16,17,18,19,20,21,22,23,24,25,26,27,28,29,30}$

sPS is a very industrially promising material due to its high melting point (ca. $270{ }^{\circ} \mathrm{C}$ ), high crystallinity, low dielectric constant and good chemical and heat resistances. ${ }^{31}$ However, all the existing rare-earth catalytic systems face difficulties to meet industrial requirements, especially operating at very high styrene-to-catalyst ratios, notably due to the fact that the precursors and corresponding active species are quite sensitive to protic and oxygen

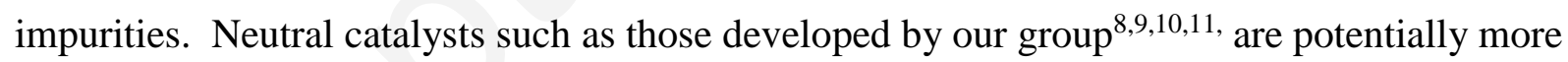
stable than cationic complexes. Also, the fact that these neutral allyl-complexes are based on more abundant and hence cheaper rare-earth metals $(\mathrm{Nd}, \mathrm{Sm})$ than scandium typically used in cationic systems can make them attractive from an industrial point of view.

In this work, we report on a new series of allyl $\{\mathrm{Cp} / \mathrm{Flu}\}$ ansa-lanthanidocenes complexes, based on the prototype system $\mathbf{I},{ }^{9}$ with various substituents at the fluorenyl and one-carbon bridge and with different metal centers (Scheme 1). Our main objectives were to assess relationship between these two essential parameters and styrene polymerization performances in order to develop more stable and effective catalytic systems. Hence, we 
demonstrate the high catalytic efficiency, combining high productivity and high syndioselectivity, of the allyl $\{\mathrm{Cp} / \mathrm{Flu}\}$ systems under severe polymerization conditions. The introduction of bulky substituents onto the fluorenyl ligand can result in very dissimilar outcomes: systems with substituents in 2,7- positions are stable under harsher polymerization conditions, while those having substituents in 3,6- positions are all inactive. In order to clarify these observations and to obtain further insights about the factors that control the formation of sPS, the first three insertion steps for these systems have been investigated by DFT.
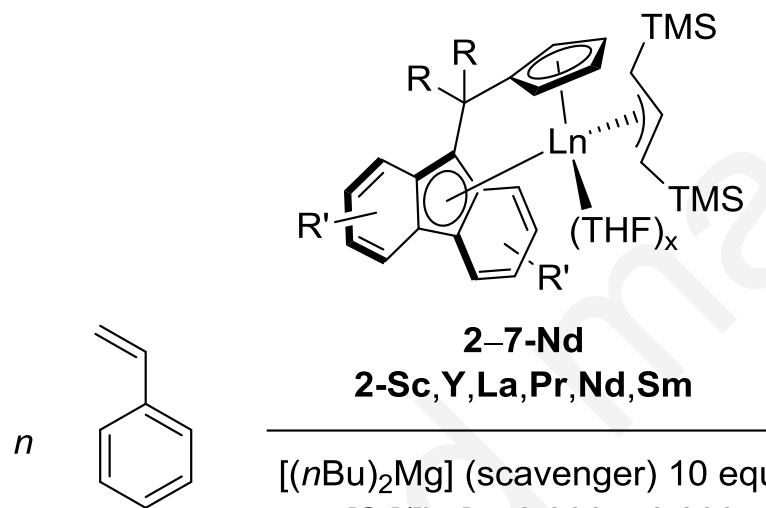

2-7-Nd

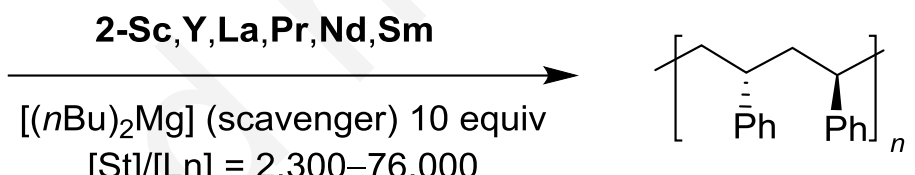

$[\mathrm{St}] /[\mathrm{Ln}]=2,300-76,000$

$60-140{ }^{\circ} \mathrm{C}$

Scheme 1. Allyl $\{\mathrm{Cp} / \mathrm{Flu}\}$ ansa-lanthanidocenes prepared in this study and used as singlecomponent catalysts for highly syndioselective styrene polymerization.

\section{Results and Discussion}

Synthesis of proligands. One-carbon-bridged proligands $\left\{\mathrm{R}_{2} \mathrm{C}\left(\mathrm{C}_{5} \mathrm{H}_{4}\right) \mathrm{H}\left(\mathrm{R}^{\prime} \mathrm{R}^{\prime} \mathrm{Flu}\right) \mathrm{H}\right\}$ (1-7-H2, Scheme 2) were synthesized in high yields (55-90\%) by nucleophilic addition of the corresponding substituted fluorenyl anion onto the corresponding $6,6^{\prime}-\mathrm{R}_{2}$-fulvenes $(\mathrm{R}=\mathrm{Me}$, Ph). ${ }^{20,32,33,34}$ Compounds $\mathbf{1}-\mathbf{7}-\mathbf{H}_{\mathbf{2}}$ were isolated as air-stable powders and were characterized by NMR spectroscopy. 

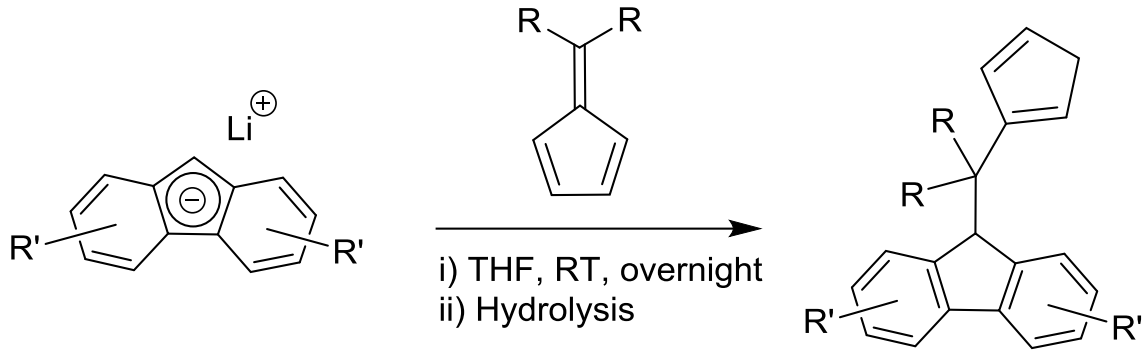

$$
\begin{aligned}
\mathbf{1}-\mathrm{H}_{2}(\mathrm{R} & \left.=\mathrm{Me}, \mathrm{R}^{\prime}=\mathrm{H}\right)(86 \%) \\
\mathbf{2}-\mathrm{H}_{2}(\mathrm{R} & \left.=\mathrm{Me}, \mathrm{R}^{\prime}=2,7-t \mathrm{Bu}_{2}\right)(73 \%) \\
\mathbf{3}-\mathrm{H}_{\mathbf{2}}(\mathrm{R} & \left.=\mathrm{Me}, \mathrm{R}^{\prime}=2,3,6,7-\mathrm{Oct}_{2}\right)(79 \%) \\
\mathbf{4}-\mathrm{H}_{\mathbf{2}}(\mathrm{R} & \left.=\mathrm{Ph}, \mathrm{R}^{\prime}=\mathrm{H}\right)(55 \%) \\
\mathbf{5}-\mathrm{H}_{\mathbf{2}}(\mathrm{R} & \left.=\mathrm{Me}, \mathrm{R}^{\prime}=3,6-t \mathrm{Bu}_{2}\right)(76 \%) \\
\mathbf{6}-\mathrm{H}_{\mathbf{2}}(\mathrm{R} & =\mathrm{Me}, \mathrm{R}^{\prime}=2,7-\left[\mathrm{CMe}_{2} \mathrm{Ph}_{2}\right)(77 \%) \\
\mathbf{7}-\mathrm{H}_{\mathbf{2}}(\mathrm{R} & \left.=\mathrm{Me}, \mathrm{R}^{\prime}=2,7-\left[\mathrm{CMePh}_{2}\right]_{2}\right)(90 \%) \\
\text { Oct } & =\text { octamethyloctahydrodibenzo }
\end{aligned}
$$

Scheme 2. Synthesis of $\{\mathrm{Cp} / \mathrm{Flu}\} \mathrm{H}_{2}$ proligands $\mathbf{1}-\mathbf{7}-\mathbf{H}_{2}$

Synthesis and structure of complexes. Allyl ansa-lanthanidocene complexes were prepared from $\mathrm{LnCl}_{3}(\mathrm{THF})_{x}$, allyl potassium salt $\left(1,3-\mathrm{C}_{3} \mathrm{H}_{3} \mathrm{TMS}_{2}\right) \mathrm{K}$ and the corresponding ligand dianion $\{\mathrm{Cp} / \mathrm{Flu}\}^{2-}$, generated in situ by reaction with 2.1 equiv of $\mathrm{BnK}$ (Scheme 3 , see Experimental Section for details). One-pot metathesis reactions of these salts in diethyl ether afforded allyl ansa-lanthanidocenes 2-7-Nd and 2-(Y, Sc, Sm, La, Pr) in moderate to good yields (25-84\%). Unexpectedly, a quite different bis(allyl) ate complex 1-Nd-K(allyl) was also obtained $(22 \%)$ under the same reaction conditions. These complexes have good solubility at room temperature in common solvents, even in aliphatic hydrocarbons such as heptane, and they are stable at room temperature when stored in a glovebox. 

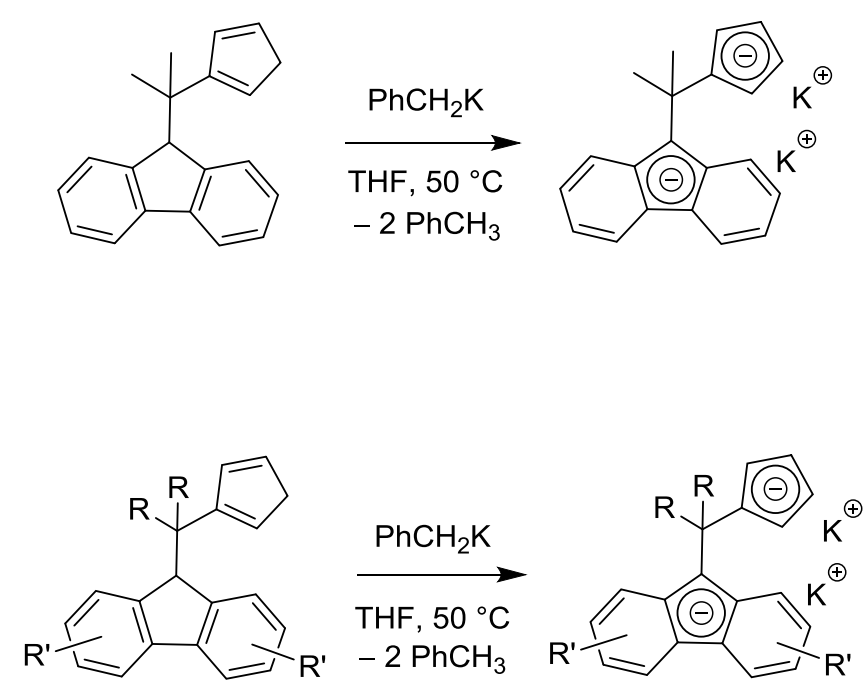

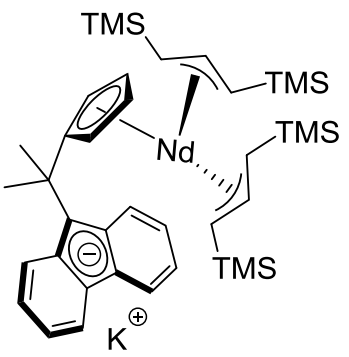

1-Nd-K(allyl) (22\%)

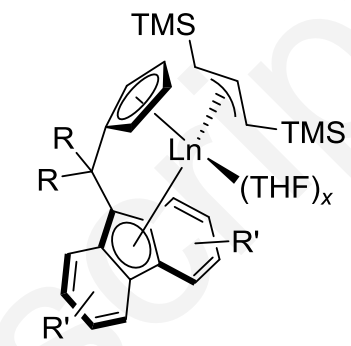

1-Nd $\left(\mathrm{R}=\mathrm{Me}, \mathrm{R}^{\prime}=\mathrm{H}\right)$ (not obtained)

2-Nd ( $\left.\mathrm{R}=\mathrm{Me}, \mathrm{R}^{\prime}=2,7-\mathrm{tBu}_{2}, x=1\right)(25 \%)$

3-Nd $\left(R=M e, R^{\prime}=2,3,6,7-\mathrm{Oct}_{2}, x=1\right)(52 \%)$

4-Nd $\left(\mathrm{R}=\mathrm{Ph}, \mathrm{R}^{\prime}=\mathrm{H}, x=1\right)(29 \%)$

5-Nd $\left(\mathrm{R}=\mathrm{Me}, \mathrm{R}^{\prime}=3,6-\mathrm{BBu}_{2}, x=1\right)(37 \%)$

6-Nd $\left(\mathrm{R}=\mathrm{Me}, \mathrm{R}^{\prime}=2,7-\left[\mathrm{CMe}_{2} \mathrm{Ph}\right]_{2}, x=1\right)(75 \%)$

7-Nd $\left(\mathrm{R}=\mathrm{Me}, \mathrm{R}^{\prime}=2,7-\left[\mathrm{CMePh}_{2}\right]_{2}, x=1\right)(83 \%)$

2-Sc $\left(\mathrm{R}=\mathrm{Me}, \mathrm{R}^{\prime}=2,7-t \mathrm{Bu}_{2}, x=0\right)(72 \%)$

2-Y $\left(\mathrm{R}=\mathrm{Me}, \mathrm{R}^{\prime}=2,7-\mathrm{BBu}_{2}, x=0\right)(71 \%)$

2-La $\left(\mathrm{R}=\mathrm{Me}, \mathrm{R}^{\prime}=2,7-\mathrm{BBu}_{2}, x=1\right)(78 \%)$

2-Sm $\left(\mathrm{R}=\mathrm{Me}, \mathrm{R}^{\prime}=2,7-\mathrm{BBu}_{2}, x=1\right)(58 \%)$

$2-\operatorname{Pr}\left(\mathrm{R}=\mathrm{Me}, \mathrm{R}^{\prime}=2,7-\mathrm{Bu}_{2}, x=1\right)(84 \%)$

Scheme 3. Synthesis of allyl ansa-lanthanidocenes 1-Nd-K(allyl), 2-7-Nd, 2-

(Sc,Y,La,Sm,Pr).

The ${ }^{1} \mathrm{H}$ and ${ }^{13} \mathrm{C}$ NMR spectra of diamagnetic complexes 2-Y, 2-Sc and 2-La recorded in $\mathrm{C}_{6} \mathrm{D}_{6}$ at room temperature all exhibit single patterns of signals (Figures $\mathrm{S} 8-\mathrm{S} 13$ ), consistent with their average symmetric structures on the NMR timescale. For instance, the ${ }^{1} \mathrm{H}$ NMR spectrum of 2-Y shows three resonances for the fluorenyl moiety, two resonances for the cyclopentadienyl group, one resonance for the $\mathrm{Me}_{2} \mathrm{C}$-bridging group and one resonance for the $t \mathrm{Bu}$ group. Complex 2-La was found as a mono-THF adduct, while complexes of smaller metals (Sc and Y) appeared to be THF-free. 
Single crystals of 2-La, 2-Pr, 2-Nd, 2-Sm and 4-Nd suitable for X-ray diffraction analysis were grown from heptane solutions at $-30{ }^{\circ} \mathrm{C}$. Their solid-state molecular structures are depicted in Figures 1 and S1-S4, and selected geometrical parameters are given in Table 1 (the crystal structure of $\mathbf{5 - Y}$ is also provided in the Supporting Information; see Figure S5). In the solid state, these complexes exhibit close geometrical parameters: the cyclopentadienyl moiety exhibits a $\eta^{5}$-bonding mode, and one molecule of THF completes the coordination sphere of the metal center. Reduced coordination modes of the fluorenyl moiety were observed, as judged by the significant difference in the $\mathrm{M}-\mathrm{C}(\mathrm{Flu})$ distances, consistent with $\eta^{3}$-bonding in 2-La, 2-Pr, 2-Nd and 2-Sm and an $\eta^{2}$-bonding in 4-Nd. Such reduced hapticity of the coordinated fluorenyl moiety was already observed in the prototype molecule I. ${ }^{9}$ Comparison along the series 2-La, 2-Pr, 2-Nd and 2-Sm allows assessing the influence of the metal center on bond lengths and bite angles $\left(\mathrm{M}-\mathrm{Flu}_{\mathrm{cent}}=2.545(3)-2.622(5) \AA, \mathrm{M}-\mathrm{C} \mathrm{p}_{\text {cent }}\right.$ $=2.428(5)-2.531(6) \AA, C p_{c e n t}-\mathrm{M}-$ Flu $_{\text {cent }}$ bite angle $\left.=90.41-93.09^{\circ}\right)$. These differences in geometrical parameters clearly follow the trend of ionic radii. ${ }^{35}$ In addition, 2-Nd, 2-La, 2Sm, 2-Pr and 4-Nd exhibit a non-symmetric coordination of the allyl ligand, which is evidenced by a significant difference in bond lengths between the metal center and carbon atoms of the allyl $(\mathrm{M}-\mathrm{C}(23)-\mathrm{M}-\mathrm{C}(21)=0.17,0.22,0.25$ and $0.26 \AA$, respectively). This discrepancy was less pronounced in complex $\mathbf{I}\left(\mathrm{M}-\mathrm{C}(23)-\mathrm{M}-\mathrm{C}(21)=0.07 \AA\right.$ ) ${ }^{9}$

Single crystals of $\mathbf{1 - N d - K ( a l l y l ) ~ w e r e ~ o b t a i n e d ~ f r o m ~ a ~ t o l u e n e ~ s o l u t i o n ~ a t ~ r o o m ~}$ temperature. The Nd center bears two allylic groups, both featuring symmetric $\eta^{3}-$ coordination mode. The fluorenyl ligand is coordinated with two potassium atoms through both central five-membered and six-membered rings. Hence, 1-Nd-K(allyl) adopts in the solid state a coordination polymer structure built up via the fluorenyl moiety of the ligand and the potassium cation (Figure 2). 
Table 1. Selected bond distances $(\AA \dot{)})$ and angles (deg) for complexes $\mathbf{I},{ }^{9} \mathbf{2}$-Nd, 4-Nd, 2-La,

2-Sm, 2-Pr and 1-Nd-K(allyl).

\begin{tabular}{|c|c|c|c|c|c|c|c|}
\hline & $\mathbf{I}^{a}$ & 2-Nd & 4-Nd & 2-La & 2-Sm & 2-Pr & 1-Nd-K(allyl) \\
\hline$M-C(23)$ & $2.656(12)$ & $2.636(5)$ & $2.620(3)$ & $2.715(5)$ & $2.603(3)$ & $2.662(4)$ & $2.733(4)$ \\
\hline $\mathbf{M}-\mathbf{C}(\mathbf{2 2})$ & $2.700(11)$ & $2.757(4)$ & $2.758(3)$ & $2.813(5)$ & $2.736(3)$ & $2.764(4)$ & $2.749(4)$ \\
\hline$M-C(21)$ & $2.725(9)$ & $2.859(5)$ & $2.880(4)$ & $2.855(5)$ & $2.856(4)$ & $2.830(4)$ & $2.720(4)$ \\
\hline $\mathbf{M}-\mathbf{C}(\mathbf{3 1})$ & - & - & - & - & - & - & $2.740(4)$ \\
\hline $\mathbf{M}-\mathbf{C}(32)$ & - & - & - & - & - & - & $2.783(4)$ \\
\hline $\mathbf{M}-\mathbf{C}(\mathbf{3 3})$ & - & - & - & - & - & - & $2.766(4)$ \\
\hline $\mathbf{M}-\mathbf{C}(\mathbf{9})$ & $2.673(8)$ & $2.702(4)$ & $2.722(3)$ & 2.754(5) & $2.680(3)$ & $2.719(4)$ & $3.287(4)$ \\
\hline $\mathbf{M}-\mathbf{C}(\mathbf{1 0})$ & $2.767(10)$ & $2.799(4)$ & $2.701(3)$ & $2.832(5)$ & $2.772(3)$ & $2.812(4)$ & - \\
\hline M-C(13) & $2.825(10)$ & $2.800(4)$ & $2.871(3)$ & $2.856(5)$ & $2.782(3)$ & $2.810(4)$ & - \\
\hline $\mathbf{M}-\mathbf{C}(11)$ & $2.935(10)$ & $2.892(4)$ & $2.910(3)$ & $2.987(4)$ & $2.873(3)$ & $2.914(4)$ & - \\
\hline $\mathbf{M}-\mathbf{C}(\mathbf{1 2})$ & $2.982(10)$ & $2.908(4)$ & $3.011(4)$ & $3.009(4)$ & $2.905(3)$ & $2.929(4)$ & - \\
\hline M-Flucent ${ }^{b}$ & $2.559(9)$ & $2.570(4)$ & $2.572(4)$ & $2.622(5)$ & $2.545(3)$ & $2.584(4)$ & - \\
\hline$[\mathbf{M}-\mathbf{C}(\mathbf{1 2})]-[\mathbf{M}-\mathbf{C}(\mathbf{9})]^{c}$ & $0.309(10)$ & $0.206(4)$ & $0.289(4)$ & $0.255(5)$ & $0.255(3)$ & $0.210(4)$ & - \\
\hline $\mathbf{M}-\mathbf{C}(\mathbf{1})$ & $2.695(9)$ & $2.680(4)$ & $2.692(3)$ & $2.754(5)$ & $2.661(3)$ & $2.707(4)$ & $2.705(3)$ \\
\hline $\mathbf{M}-\mathbf{C}(\mathbf{2})$ & $2.697(10)$ & $2.730(5)$ & $2.712(4)$ & $2.792(6)$ & $2.707(5)$ & $2.754(4)$ & 2.674(4) \\
\hline $\mathbf{M}-\mathbf{C}(\mathbf{3})$ & $2.766(10)$ & $2.802(5)$ & $2.780(4)$ & $2.872(5)$ & $2.779(4)$ & $2.822(5)$ & $2.715(5)$ \\
\hline $\mathbf{M}-\mathbf{C}(4)$ & $2.806(10)$ & $2.772(5)$ & $2.758(4)$ & $2.844(6)$ & $2.748(4)$ & $2.791(4)$ & $2.757(5)$ \\
\hline $\mathbf{M}-\mathbf{C}(\mathbf{5})$ & $2.757(9)$ & $2.674(4)$ & $2.686(3)$ & $2.746(5)$ & $2.651(3)$ & $2.700(4)$ & $2.762(4)$ \\
\hline $\mathrm{M}-\mathrm{Cp}_{\mathrm{Cent}}{ }^{c}$ & 2.464(9) & $2.457(5)$ & $2.447(4)$ & $2.531(6)$ & $2.428(5)$ & $2.480(5)$ & $2.446(5)$ \\
\hline $\mathbf{M}-\mathbf{O}(\mathbf{1})$ & $2.494(9)$ & $2.467(3)$ & $2.501(2)$ & $2.554(3)$ & $2.449(3)$ & $2.494(3)$ & - \\
\hline $\mathbf{C p}_{\text {Cent }}-\mathbf{M}-$ FluCent $^{b, d}$ & $93.88(5)$ & $92.23(5)$ & $90.68(4)$ & $90.41(6)$ & $93.09(5)$ & $91.63(5)$ & - \\
\hline $\mathrm{C}(23)-\mathrm{C}(22)$ & $1.287(18)$ & $1.411(6)$ & $1.405(5)$ & $1.405(6)$ & $1.415(4)$ & $1.408(7)$ & $1.392(7)$ \\
\hline$C(22)-C(21)$ & $1.310(2)$ & $1.358(6)$ & $1.378(5)$ & $1.380(6)$ & $1.380(4)$ & $1.378(6)$ & $1.400(5)$ \\
\hline $\mathbf{C}(31)-\mathbf{C}(32)$ & - & - & - & - & - & - & $1.389(5)$ \\
\hline $\mathbf{C}(32)-C(33)$ & - & - & - & - & - & - & $1.398(7)$ \\
\hline
\end{tabular}

${ }^{a}$ From ref. 9. ${ }^{b}$ Centroid calculated considering an $\eta^{3}$-coordination mode. ${ }^{c}$ Difference of bond distance between the metal center and $\mathrm{C} 9$ and $\mathrm{C} 12$ atoms of fluorenyl to assess the hapticity mode. ${ }^{\mathrm{d}}$ Centroid calculated considering an $\eta^{5}$-coordination mode. 


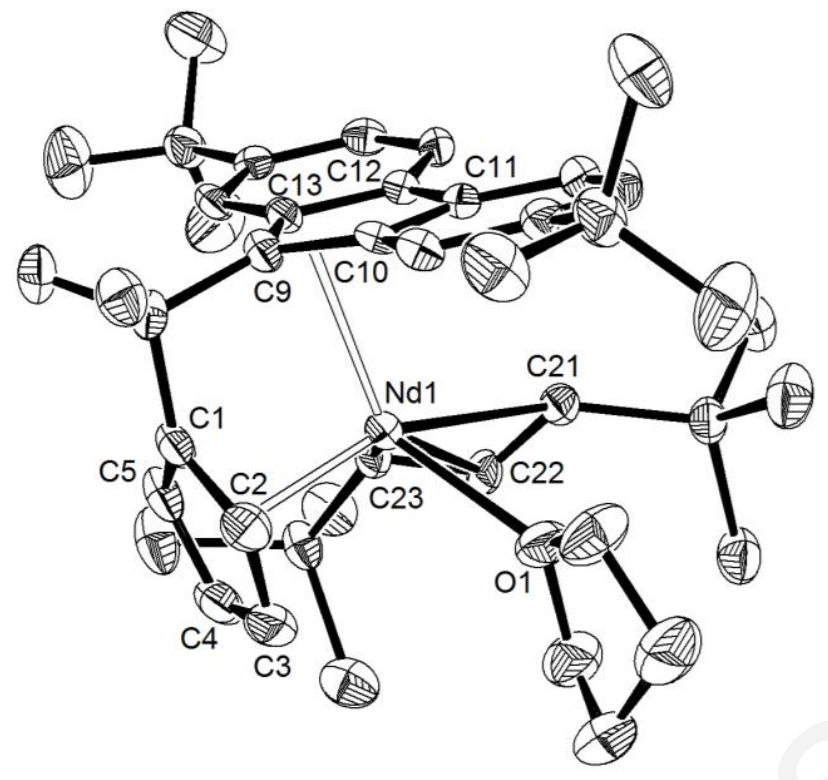

Figure 1. Crystal structure of 2-Nd (ellipsoids drawn at the 50\% probability level; all hydrogen atoms are omitted for clarity)

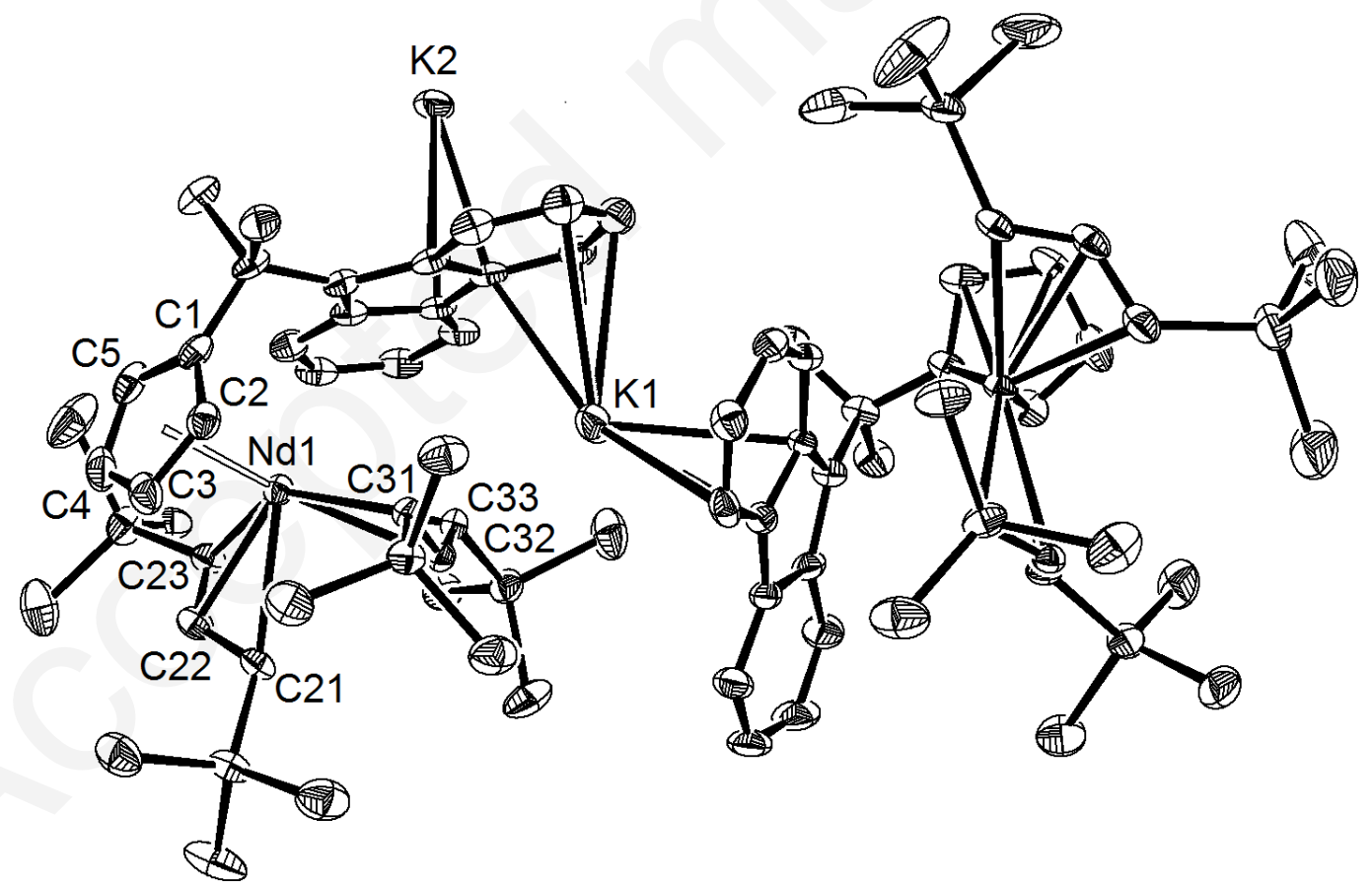

Figure 2. Crystal structure of 1-Nd-K(allyl) (ellipsoids drawn at the 50\% probability level; all hydrogen atoms are omitted for clarity) 
Styrene homopolymerization studies. Compounds 1-Nd-K(allyl), 2-7-Nd and 2-

Sc,Y, La, Sm, Pr were evaluated in the homopolymerization of styrene. For comparison purposes, catalytic performances were determined under identical conditions (see Table 2). In particular, it was chosen to combine the complexes with a few equiv of $(n \mathrm{Bu})_{2} \mathrm{Mg}$ as a scavenger, since experiments performed without $\mathrm{R}_{2} \mathrm{Mg}$ gave less reproducible results, most likely due to the high sensitivity of the complexes towards impurities (vide infra).

Table 2. Styrene polymerizations catalyzed by 1-Nd-K(allyl), 2-7-Nd and 2-Sc,Y,La,Sm,Pr

$a$

\begin{tabular}{|c|c|c|c|c|c|c|c|c|c|c|}
\hline Entry & Complex & $\begin{array}{l}\text { Yield } \\
\text { PS }{ }^{b} \\
{[\%]}\end{array}$ & $\begin{array}{c}\text { Prod. }^{c} \\
{\left[\mathrm{kgPS} \cdot \mathrm{mol}^{-1} \cdot \mathrm{h}^{-1}\right]}\end{array}$ & $\begin{array}{l}T_{\mathrm{m}}{ }^{d} \\
{\left[{ }^{\circ} \mathrm{C}\right]}\end{array}$ & $\begin{array}{l}T_{\mathrm{c}}{ }^{d} \\
{\left[{ }^{\circ} \mathrm{C}\right]}\end{array}$ & $\begin{array}{l}T_{\mathrm{g}}{ }^{d} \\
{\left[{ }^{\circ} \mathrm{C}\right]}\end{array}$ & $\begin{array}{l}\Delta H_{\mathrm{m}}{ }^{d} \\
{\left[\mathrm{~J} \cdot \mathrm{g}^{-1}\right]}\end{array}$ & $\begin{array}{c}M_{\mathrm{n}} \times 10^{-3} \\
{\left[\mathrm{~g} \cdot \mathrm{mol}^{-1}\right]^{e}}\end{array}$ & $\bigoplus_{M}^{e}$ & $\begin{array}{l}{[r]^{5}} \\
{[\%]^{f}}\end{array}$ \\
\hline 1 & I & 45 & 212 & no & no & 84 & no & 18.6 & 1.7 & 55 \\
\hline 2 & 1-Nd-K(allyl) & 21 & 101 & 225,240 & 205 & 93 & 23.4 & 11.3 & 1.7 & 71 \\
\hline 3 & 2-Nd & 54 & 284 & 251,264 & 233 & 95 & 35.4 & 20.0 & 2.5 & 88 \\
\hline 4 & 3-Nd & 0 & 0 & - & - & - & - & - & - & - \\
\hline 5 & 4-Nd & 15 & 75 & 234,246 & 215 & 92 & 24.6 & 10.8 & 1.8 & 74 \\
\hline 6 & $5-\mathrm{Nd}$ & 0 & 0 & - & - & - & - & - & - & - \\
\hline 7 & 6-Nd & 14 & 66 & 245,256 & 231 & no & 37.1 & 8.2 & 1.8 & 78 \\
\hline 8 & 7-Nd & 13 & 62 & 243,255 & 228 & 94 & 39.9 & 10.6 & 1.7 & 83 \\
\hline 9 & $2-Y$ & 5 & 21 & 250 & 216 & 97 & 8.4 & nd & nd & $n d$ \\
\hline 10 & 2-Sc & 0 & 0 & - & - & - & - & - & - & - \\
\hline 11 & 2-Sm & 22 & 108 & 254,266 & 238 & 96 & 33.8 & 18.0 & 2.4 & 86 \\
\hline 12 & 2-La & 22 & 103 & 222 & 163 & 96 & 14.7 & 16.1 & 1.9 & 63 \\
\hline 13 & 2-Pr & 46 & 221 & 257 & 220 & 98 & 30.8 & 20.1 & 1.9 & 83 \\
\hline
\end{tabular}

${ }^{a}$ General conditions: $10-15 \mu \mathrm{mol}$ of Ln complex; $[\mathrm{St}] /[\mathrm{Ln}]=2,300 ;$ [styrene $]=4.4 \mathrm{M}$ (in cyclohexane); $[\mathrm{Mg}] /[\mathrm{Ln}]=10$; $\mathrm{T}_{\text {polym }}=60{ }^{\circ} \mathrm{C} ; 30 \mathrm{~min}$; styrene purified through neutral alumina, stirring on $\mathrm{CaH}_{2}$, trap-to-trap vacuum distillation and stored in the fridge of the glovebox on $3 \AA$ molecular sieves; $n d$ : not determined; $n o$ : not observed. ${ }^{b}$ Isolated yield of sPS collected after precipitation in $\mathrm{MeOH} .{ }^{c}$ Productivity calculated over the whole reaction time. ${ }^{d}$ Determined by DSC from second run. ${ }^{e}$ Determined by SEC at $135{ }^{\circ} \mathrm{C}$ in $1,2,4$-trichlorobenzene. ${ }^{f}$ Determined by ${ }^{13} \mathrm{C}$ NMR spectroscopy considering the methylene region $(43-47 \mathrm{ppm})$.

These results allowed highlighting several trends:

1) The nature of substitution on the fluorenyl moiety has a tremendous effect. First, introduction of the $t \mathrm{Bu}$ groups on the 2,7-positions enabled a slightly more productive and 
more stereoselective catalyst $\mathbf{2}$-Nd with respect to the prototype system I (compare entries 1 and 3). Second, replacement of the $t \mathrm{Bu}$ groups on the 2,7-positions in 2-Nd by bulkier $\mathrm{CMe}_{2} \mathrm{Ph}$ - or $\mathrm{CMePh}_{2}$ - groups (complexes 6-Nd and 7-Nd) also results in less productive catalytic systems (entries 3, 7 and 8). Third, the presence of $t \mathrm{Bu}$ substituents at the 3,6positions induces a dramatic drop in productivity (complexes $\mathbf{3 - N d}$ and $\mathbf{5 - N d}$, entries 4 and $6)$.

2) Replacement of the $\mathrm{Me}_{2} \mathrm{C}$ - bridge for a $\mathrm{Ph}_{2} \mathrm{C}$ - bridge resulted in slightly lower catalytic performances (compare entries 3 and 5). This trend was already documented for syndioselective propylene polymerization catalyzed by zirconium and hafnium $\{\mathrm{Cp} / \mathrm{Flu}\}$ complexes. $^{9}$

3) The polymerization productivities among the series of complexes $\mathbf{2}-\mathbf{L n}$ were found in the order $\mathrm{Nd} \approx \mathrm{Pr}>\mathrm{La} \approx \mathrm{Sm}>>\mathrm{Y}>\mathrm{Sc}$ (compare entries 3 and 9-11); complex 2-Nd was found the most productive so far (ca. $280 \mathrm{~kg} \cdot \mathrm{mol}^{-1} \cdot \mathrm{h}^{-1}$ at $60{ }^{\circ} \mathrm{C}$; vide infra) while its analogues based on small ionic radius metal centers (as $\mathrm{Y}$ or $\mathrm{Sc}$ ) were almost inactive. This trend is in line with that noticed for allyl ansa-lanthanidocenes $\left\{\mathrm{Me}_{2} \mathrm{C}\left(\mathrm{C}_{5} \mathrm{H}_{4}\right)(\mathrm{Flu})\right\} \mathrm{Ln}\left(\eta^{3}-\mathrm{C}_{3} \mathrm{H}_{5}\right)(\mathrm{THF}){ }^{36}$ for which the neodymium congener appeared also to be the most active. The "supremacy" of neodymium systems in styrene or diene polymerization is a regular, although poorly understood phenomenon. ${ }^{37,38,39,40}$

Further polymerization tests were carried out with complex 2-Nd to optimize the polymerization conditions and improve on the catalytic performance (Table 3). Preliminary experiments were conducted to assess the influence of $(n \mathrm{Bu})_{2} \mathrm{Mg}$ since the latter compound could act also as a chain-transfer agent. ${ }^{41,42}$ As expected, the $M_{\mathrm{n}}$ values of sPS decreased to some extent when the $[\mathrm{Mg}] /[\mathrm{Ln}]$ ratio increased; that is by a factor of ca. 3, 4 and 7 when 10 , 50 and 200 equiv of $(n \mathrm{Bu})_{2} \mathrm{Mg}$ were added, respectively (entries 3-6), values that are much higher than the calculated ones for an ideal chain transfer agent (Figure S24). 
Table 3. Styrene polymerizations catalyzed by $\mathbf{2 - N d}, \mathbf{S m}, \mathbf{P r}$ at high monomer loadings and high temperature. ${ }^{a}$

\begin{tabular}{|c|c|c|c|c|c|c|c|c|c|c|c|c|c|c|c|}
\hline Entry & Complex & $\begin{array}{l}{[\mathrm{St}]} \\
{[\mathrm{M}]}\end{array}$ & $\begin{array}{l}{[\mathrm{St}] /} \\
{[\mathrm{Nd}]}\end{array}$ & $\begin{array}{c}{[\mathrm{Mg}] /} \\
{[\mathrm{Ln}]}\end{array}$ & $\begin{array}{l}\mathrm{T}_{\text {polym }} \\
{\left[{ }^{\circ} \mathrm{C}\right]}\end{array}$ & $\begin{array}{l}\text { Time } \\
{[\mathrm{min}]}\end{array}$ & $\begin{array}{l}\text { Yield } \\
\text { PS }^{b} \\
{[\%]} \\
\end{array}$ & $\begin{array}{c}\text { Prod. }^{c} \\
{[\mathrm{kgPS} .} \\
\left.\mathrm{mol}^{-1} \cdot \mathrm{h}^{-1}\right]\end{array}$ & $\begin{array}{c}T_{\mathrm{m}}{ }^{d} \\
{\left[{ }^{\circ} \mathrm{C}\right]}\end{array}$ & $\begin{array}{c}T_{\mathrm{c}}{ }^{d} \\
{\left[{ }^{\circ} \mathrm{C}\right]}\end{array}$ & $\begin{array}{c}T_{\mathrm{g}}{ }^{d} \\
{\left[{ }^{\circ} \mathrm{C}\right]}\end{array}$ & $\begin{array}{l}\Delta H_{\mathrm{m}}{ }^{d} \\
{\left[\mathrm{~J} \cdot \mathrm{g}^{-1}\right]}\end{array}$ & $\begin{array}{c}M_{\mathrm{n}} \times 10^{-3} \\
{\left[\mathrm{~g} \cdot \mathrm{mol}^{-1}\right]^{e}}\end{array}$ & $\bigoplus_{\mathrm{M}}{ }^{e}$ & $\begin{array}{c}{[r]^{5 f}} \\
{[\%]}\end{array}$ \\
\hline 1 & I & 4.4 & 2,300 & 0 & 60 & 30 & 37 & 166 & 256 & 213 & 101 & 24.0 & 62.0 & 1.5 & 55 \\
\hline 2 & I & 4.4 & 2,300 & 10 & 60 & 30 & 45 & 212 & no & no & 84 & no & 18.6 & 1.7 & 55 \\
\hline 3 & $2-\mathrm{Nd}$ & 4.4 & 2,300 & 0 & 60 & 30 & 30 & 156 & 252,260 & 216 & 102 & 22.1 & 58.8 & 5.3 & $n d$ \\
\hline 4 & $2-\mathrm{Nd}$ & 4.4 & 2,300 & 10 & 60 & 30 & 54 & 284 & 251,264 & 233 & 95 & 35.4 & 20.0 & 2.5 & 88 \\
\hline 5 & 2-Nd & 4.4 & 2,300 & 50 & 60 & 30 & 50 & 241 & 250 & 214 & 96 & 25.3 & 14.9 & 1.9 & 81 \\
\hline 6 & 2-Nd & 4.4 & 2,300 & 200 & 60 & 30 & 49 & 233 & 225 & 181 & 87 & 17.4 & 8.4 & 1.8 & $n d$ \\
\hline 7 & I & 4.4 & 20,000 & 10 & 120 & 120 & 76 & 790 & no & no & 97 & no & 22.4 & 2.0 & 57 \\
\hline 8 & $2-\mathrm{Nd}$ & 4.4 & 20,000 & 10 & 120 & 120 & 72 & 745 & 241,258 & 221 & 98 & 29.2 & 24.9 & 3.4 & 87 \\
\hline 9 & 2-Nd & 4.4 & 40,000 & 10 & 140 & 120 & 69 & 1,438 & 235,251 & 213 & 100 & 24.3 & 24.5 & 2.1 & 71 \\
\hline 10 & 2-Sm & 4.4 & 40,000 & 10 & 140 & 120 & 68 & 1,417 & 225 & no & 100 & 2.2 & 24.7 & 2.2 & 60 \\
\hline 11 & 2-Pr & 4.4 & 40,000 & 10 & 140 & 120 & 81 & 1,688 & 249 & 206 & 100 & 24.3 & 27.0 & 2.1 & 78 \\
\hline 12 & 2-Nd & 4.4 & 40,000 & 0 & 140 & 120 & 33 & 683 & no & no & 105 & no & $n d$ & $n d$ & Atactic \\
\hline $13^{g}$ & 2-Nd & 4.4 & 40,000 & 0 & 140 & 120 & 3 & 65 & no & no & 109 & no & $n d$ & $n d$ & $n d$ \\
\hline 14 & 2-Nd & Bulk $^{h}$ & 74,000 & 9 & 100 & 45 & 23 & 2,360 & 260 & 203 & 100 & 17.4 & 30.7 & 10.9 & 77 \\
\hline 15 & 2-Nd & Bulk $^{h}$ & 76,000 & 9 & 120 & 50 & 48 & 4,560 & 257 & 194 & 99 & 18.7 & 26.6 & 7.7 & 71 \\
\hline
\end{tabular}

${ }^{a}$ General conditions: $10-15 \mu \mathrm{mol}$ of Ln complex; [styrene] $=4.4 \mathrm{M}$ (in cyclohexane at $60{ }^{\circ} \mathrm{C}$ or $n$-dodecane at $120-140{ }^{\circ} \mathrm{C}$ ) or in bulk (no solvent); styrene purified through neutral alumina, stirring on $\mathrm{CaH}_{2}$, trap-to-trap vacuum distillation and stored in the fridge of the glovebox on $3 \AA \hat{~ m o l e c u l a r ~ s i e v e s ; ~} n d$ : not determined; no: not observed. ${ }^{b}$ Isolated yield of sPS collected after precipitation in $\mathrm{MeOH} .{ }^{c}$ Productivity calculated over the whole reaction time. ${ }^{d}$ Determined by DSC from second run. ${ }^{e}$ Determined by SEC at $135{ }^{\circ} \mathrm{C}$ in 1,2,4-trichlorobenzene. ${ }^{f}$ Determined by ${ }^{13} \mathrm{C}$ NMR spectroscopy. ${ }^{g}$ Repetition of entry 12 to illustrate the reproducibility under these conditions. ${ }^{h}\left[\mathrm{Me}_{2} \mathrm{C}\left(\mathrm{C}_{5} \mathrm{H}_{4}\right)(\mathrm{Flu})\right] \mathrm{Nd}\left(1,3-\mathrm{C}_{3} \mathrm{H}_{5}\right)(\mathrm{THF}) .{ }^{h}$ Reactions conducted in a 2-L reactor on $500 \mathrm{~g}$ styrene without solvent.

The actual poor chain transfer ability of binary systems $2-\mathbf{L n} /(n \mathrm{Bu})_{2} \mathrm{Mg}$ eventually allowed to work at high $[\mathrm{St}] /[\mathrm{Ln}]$ ratio, without significant detrimental impact on the molecular weight. Working at very high $[\mathrm{St}] /[\mathrm{Ln}]$ ratio remains quite challenging, as larger monomer loadings necessarily induce more impurities. In our case, 2-Nd, 2-Sm and 2-Pr proved able to withstand up to 40,000 equiv of styrene at the lab scale (12-17 g, entries 8-11) and generate sPS still at temperatures as high as $120-140{ }^{\circ} \mathrm{C}$; 2 -Nd was also successfully used with up to 75,000 equiv of styrene on a half-kilogram scale under bulk conditions at 100-120 ${ }^{\circ} \mathrm{C}$ (entries 14 and 15). To our knowledge, no catalytic system based on group 3 
metals and still productive and stereoselective at such high $[\mathrm{St}] /[\mathrm{Ln}]$ ratio and temperatures has been reported yet. The maximum productivity at $120{ }^{\circ} \mathrm{C}$ (calculated for $[\mathrm{St}] /[\mathrm{Nd}]=$ 76,000 over $50 \mathrm{~min}$ ) reaches ca. $4,560 \mathrm{~kg} \cdot \mathrm{mol}^{-1} \cdot \mathrm{h}^{-1}$ with $\mathbf{2}-\mathbf{N d}$.

The beneficial presence of $(n \mathrm{Bu})_{2} \mathrm{Mg}$ as scavenger to maintain stability of the active species and hence high, reproducible productivity under such drastic conditions proved necessary (entries 9 and 12-13). Indeed, 2-Nd (as other complexes of this series) appeared to be rather unstable at very high monomer loading (styrene-to-metal > 40,000) and polymerization temperature $\left(T_{\text {polym }}>120{ }^{\circ} \mathrm{C}\right)$; in the absence of $(n \mathrm{Bu})_{2} \mathrm{Mg}$, adventitious formation of atactic polystyrene, most likely originating from thermally-initiated radical polymerization (Mayo's process), ${ }^{43}$ was observed (see e.g. entries 12 and 13). On the other hand, the stability of the catalyst can be efficiently preserved by the addition of a few equiv of $(n \mathrm{Bu})_{2} \mathrm{Mg}$, and formation of sPS was then systematically observed, whatever the reaction conditions.

Quite remarkably, the polystyrene samples produced using 2-Nd and 2-Pr as catalysts (precursors) are still highly syndiotactic despite the high polymerization temperature $\left([r]^{5}=\right.$ $71-78 \%$ at $100-140{ }^{\circ} \mathrm{C}$ vs. $81-88 \%$ at $60{ }^{\circ} \mathrm{C}$; see Table 3 , entries $8,9,11,14$ and 15 vs. entries 4, 5 and those of Table 2). With the samarium analogue, the syndiotacticity is lower $\left([r]^{5}=60 \%\right)$, as also evidenced by the noticeable decrease of the melting point and of the corresponding heat of fusion (entry 10$)$. In addition, $M_{\mathrm{n}}$ and dispersity values $([\mathrm{St}] /[\mathrm{Ln}]=$ $40,000, \mathrm{~T}_{\text {polym }}=140{ }^{\circ} \mathrm{C}$, entries $9-11$ ) were found to be independent of the nature of the metal center and quite close to those obtained at $60{ }^{\circ} \mathrm{C}$ at $[\mathrm{St}] /[\mathrm{Ln}]=2,300\left(M_{\mathrm{n}}=24.5-27.0\right.$ and $\bigoplus_{\mathrm{M}}$ $=2.1-2.2$ vs. $M_{\mathrm{n}}=20.0$ and $\left.\bigoplus_{\mathrm{M}}=2.5\right)$.

Computational studies. Recently, Castro et al. reported on a reliable computational method of choice for olefin polymerization systems, which includes solvent effects. ${ }^{44}$ This methodology was here applied to styrene polymerization promoted by 
$\left\{\mathrm{Me}_{2} \mathrm{C}\left(\mathrm{C}_{5} \mathrm{H}_{4}\right)\left(\mathrm{R}^{\prime} \mathrm{R}\right.\right.$ 'Flu $\left.)\right\} \mathrm{Nd}(\mathrm{allyl})$ systems, to evaluate the influence of substituents on the allyl moiety $\left(\mathrm{C}_{3} \mathrm{H}_{5}\right.$ vs. $\left.1,3-\mathrm{C}_{3} \mathrm{H}_{3}\left(\mathrm{SiMe}_{3}\right)_{2}\right)$ and on the fluorenyl moiety (none vs. 2,7- vs. $3,6) .{ }^{45}$

Preliminary control computations performed on $\left\{\mathrm{Me}_{2} \mathrm{C}\left(\mathrm{C}_{5} \mathrm{H}_{4}\right)(\mathrm{Flu})\right\} \mathrm{Nd}\left(\mathrm{C}_{3} \mathrm{H}_{5}\right)$ showed that inclusion of the implicit solvent model ${ }^{44}$ does not affect the chemistry discussed from previously reported gas phase results ${ }^{11}$ but does influence the barriers (see the Supporting Information for profiles; Figures S35-S37): (i) styrene insertions occur via secondary (2,1-) regioregular pathway; (ii) monomer enchainment takes place via a stationary mechanism, i.e. the incoming styrene unit coordinates onto the same site as for the previous insertion; (iii) perfect alternation of styrene's enantioface ensures syndioselectivity; (iv) computations up to the third insertion are needed to evaluate the actual tacticity of polymer. Overall, the production of syndiotactic polystyrene is thermodynamically controlled: a "down" orientation of the styrene phenyl ring (see Chart 1 ) is thermodynamically preferred at the odd $\left(1^{\text {st }}, 3^{\text {rd }}\right.$ etc) steps, while even $\left(2^{\text {nd }} \ldots\right)$ insertions occur in the "up" mode to minimize steric repulsion between the phenyl ring of the incoming styrene and the fluorenyl moiety.

DFT investigation of styrene polymerization catalyzed by $\left\{\mathrm{Me}_{2} \mathrm{C}\left(\mathrm{C}_{5} \mathrm{H}_{4}\right)(\mathrm{Flu})\right\} \mathrm{Nd}(1,3-$ $\left.\mathrm{C}_{3} \mathrm{H}_{3}\left(\mathrm{SiMe}_{3}\right)_{2}\right)(\mathbf{1 - N d})$. In order to assess the influence of $\mathrm{SiMe}_{3}$ substituents of the allyl ligand on the first steps of styrene polymerization, four different insertion modes were considered for the 2,1-pathway: the "down" and "up" orientation of the styrene phenyl ring, combined with either a "stationary" insertion, i.e. with no change of coordination site between insertions, or a "migratory" insertion, i.e. with switching of the coordination site at each step. 

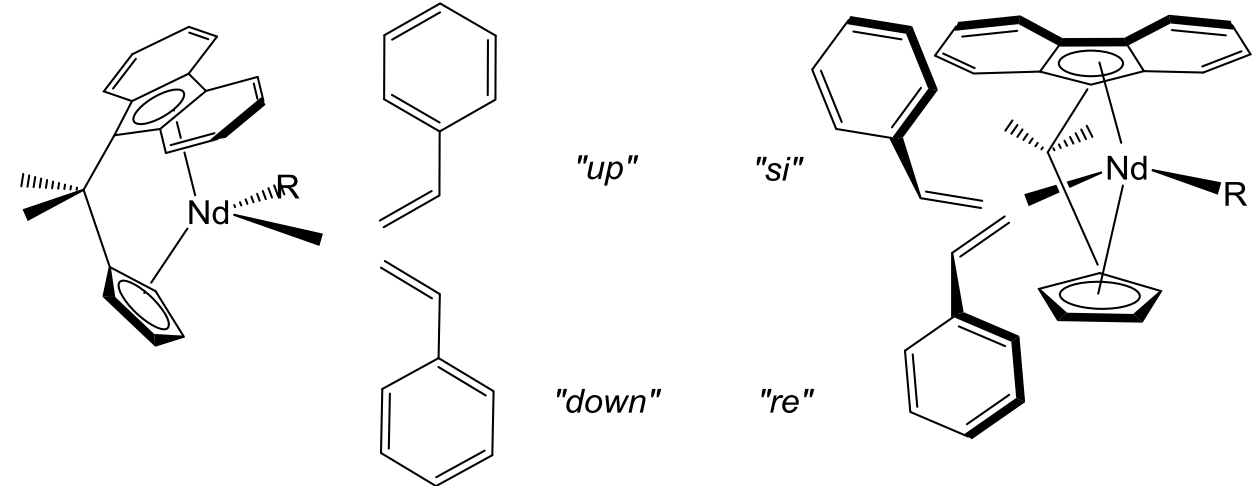

Chart 1. Nomenclature and orientation modes used for styrene insertion with respect to the ancillary ligand. Only one enantiomer of the metal catalyst used for "stationary" insertions is represented, exhibiting down-re and up-si styrene coordination modes. The opposite configurations have been employed for "migratory" insertions, viz. down-si and up-re.

i) First styrene insertion. The first insertion of styrene into the $\mathrm{Nd}-$ allyl bond represents the initiation step of the global polymerization mechanism; thus, the corresponding computed energy profiles (Figure 3) can be used for assessment of initiation efficiency of this system. The preference for the down-re-coordination/insertion (3d-re) of monomer is clearly evidenced from the lower corresponding insertion barrier $\left(\Delta H^{\#}=28.2 \mathrm{kcal} \mathrm{mol}^{-1}\right)$ as compared to that for the up-si-coordination/insertion $\left(\Delta H^{\#}=34.1 \mathrm{kcal} \mathrm{mol}^{-1}\right)$. Indeed, the transition state $\mathbf{3} \boldsymbol{u}$-si is higher in energy by $5.9 \mathrm{kcal} \mathrm{mol}^{-1}$ than $\mathbf{3} \boldsymbol{d}$-re, which is the upper limit of the method error range. ${ }^{46,47}$ The energy difference between the two geometries can be attributed to the steric hindrance, as in the less stable transition state $\mathbf{3} \boldsymbol{u}$-si the phenyl ring points toward the Flu ring (Figure S25). Also, the allyl ligand is $\eta^{2}$-coordinated (as in adduct $\mathbf{2 u}$-si), due to modification in the coordination mode of the fluorenyl ligand via its less nucleophilic 6-membered ring. ${ }^{11,48}$ No such ring slippage of the fluorenyl ligand occurred for the more stable transition state $\mathbf{3 d - r e}$, but rather a decoordination of the allyl ligand. This latter being now $\eta^{1}$-coordinated while it was $\eta^{3}$-bonded in the adduct $\mathbf{2 d}$-re $\left(\mathrm{Nd}-\mathrm{C}^{3}(\right.$ allyl $)=$ 
2.97^) (See Chart 2). The destabilizing effect of this reduced coordination lies at the origin of a much higher activation barrier of insertion than that calculated for the analogous nonsubstituted system $\left\{\mathrm{Me}_{2} \mathrm{C}\left(\mathrm{C}_{5} \mathrm{H}_{4}\right)(\mathrm{Flu})\right\} \mathrm{Nd}\left(\mathrm{C}_{3} \mathrm{H}_{5}\right)\left(28.2\right.$ vs. $17.8 \mathrm{kcal} \mathrm{mol}^{-1}$, respectively) and was corroborated by a charge analysis at the NBO level. Interestingly, the charges on the carbon atoms in the allyl ligand are $\left[\mathrm{C}^{1}\left(\right.\right.$ allyl) $(-0.88), \mathrm{C}^{2}$ (allyl) $(-0.28), \mathrm{C}^{3}$ (allyl) $\left.(-0.89)\right]$ in 3d-re and $\left[C^{1}\left(\right.\right.$ allyl) $(-0.90), C^{2}$ (allyl) $(-0.24), C^{3}$ (allyl) $\left.(-0.92)\right]$ in $\mathbf{3 u}$-si. For this insertion, there should be a nucleophilic assistance from the $C^{3}$ (allyl) carbon atom but the most nucleophilic carbon should be $\mathrm{C}^{1}($ allyl) as it ensures the $\mathrm{C}-\mathrm{C}$ coupling. Hence, sterically hindered allyl triggers a charge relocalization at the "wrong" carbon atom $\left(\mathrm{C}^{3}\right)$ that cannot really ensure the nucleophilic assistance. This results in a barrier increase $\left(\Delta H^{\#}=28.2 \mathrm{kcal}\right.$ $\mathrm{mol}^{-1}$ for $\mathbf{3 d}$-re and $\Delta H^{\#}=34.1 \mathrm{kcal} \mathrm{mol}^{-1}$ for $\mathbf{3 u}$-si) compared to those obtained in the case of $\left\{\mathrm{Me}_{2} \mathrm{C}\left(\mathrm{C}_{5} \mathrm{H}_{4}\right)(\mathrm{Flu})\right\} \mathrm{Nd}\left(\mathrm{C}_{3} \mathrm{H}_{5}\right)\left(\Delta H^{\#}=17.8 \mathrm{kcal} \mathrm{mol}^{-1}\right.$ and $20.5 \mathrm{kcal} \mathrm{mol}^{-1}$, respectively $)$ for the first styrene insertion.

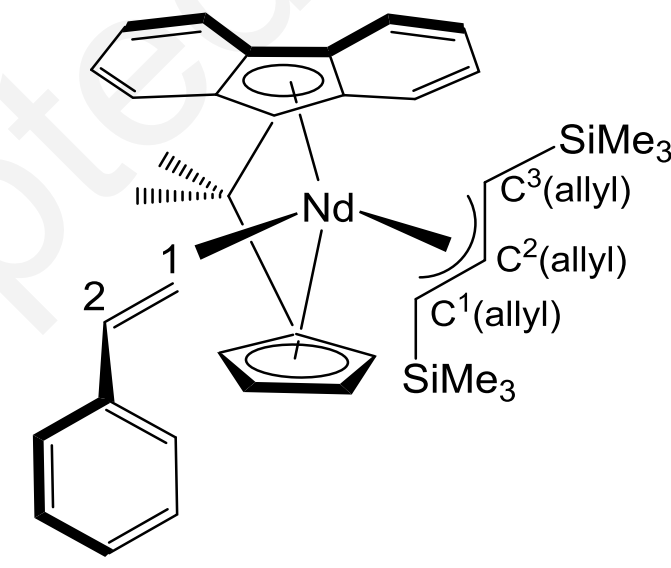

Chart 2. Numbering used for carbon atoms in the allyl ligand. 

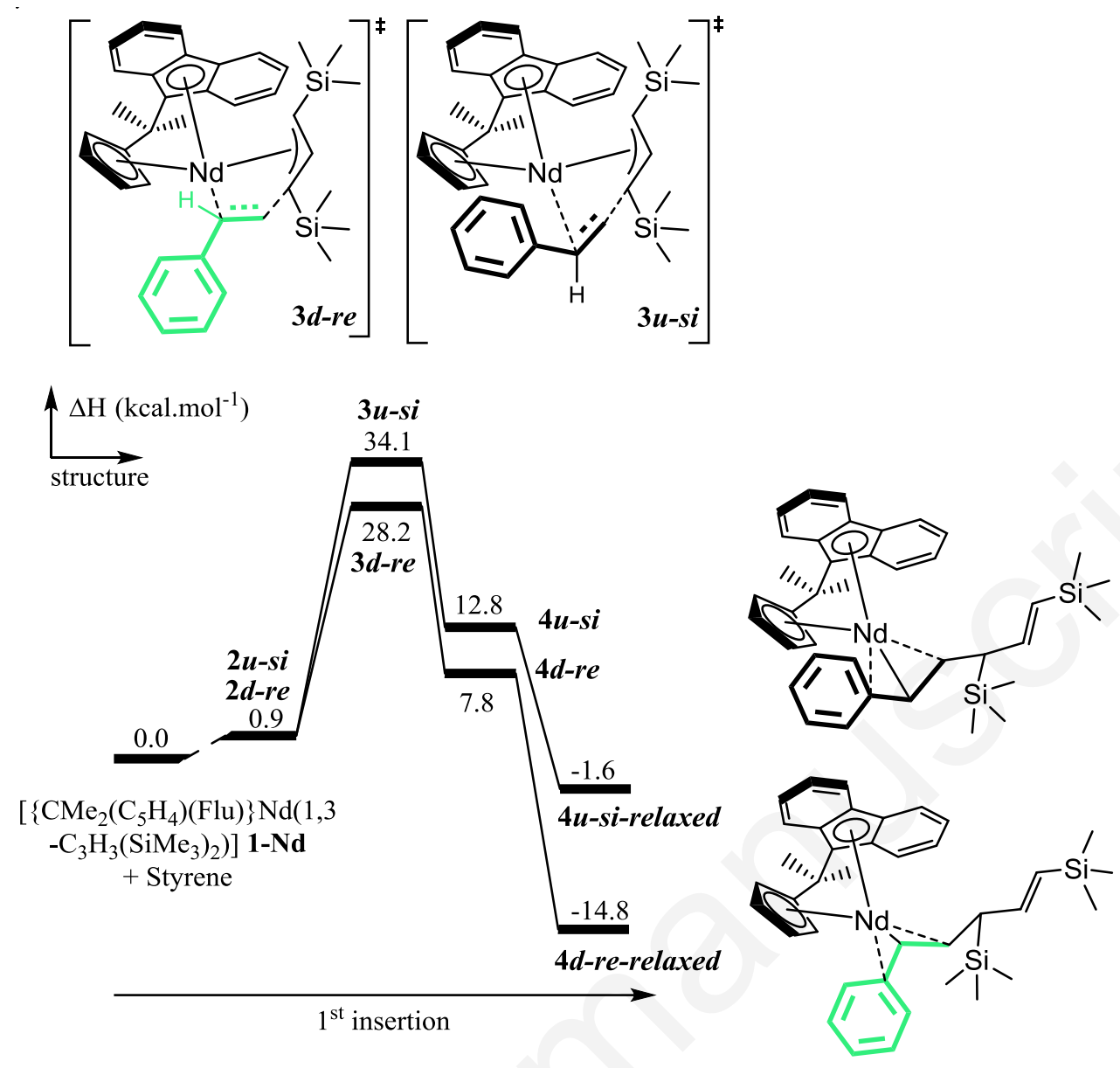

Figure 3. Energetic profiles for the first styrene insertion in $\left\{\mathrm{Me}_{2} \mathrm{C}\left(\mathrm{C}_{5} \mathrm{H}_{4}\right)(\mathrm{Flu})\right\} \mathrm{Nd}(1,3-$ $\left.\mathrm{C}_{3} \mathrm{H}_{3}\left(\mathrm{SiMe}_{3}\right)_{2}\right)(\mathbf{1 - N d})$.

Following the intrinsic reaction coordinate, the insertion reactions lead to the corresponding products $\mathbf{4} \boldsymbol{u}$-si and $\mathbf{4 d}$-re whose formation appeared to be endothermic. This stems from the fact that in $\mathbf{4} \boldsymbol{u}$-si and $\mathbf{4} \boldsymbol{d}$-re a remaining interaction between the allyl terminal double bond and the metal center (Figure S26) enforces the styryl unit to be $\eta^{1}$-bonded (as in a regular alkyl complex) and further interconversion of an alkyl to an allyl isomer is disfavored thermodynamically. Further relaxation of the polymer chain stabilizing the corresponding complexes $\mathbf{4 d - r e - r e l a x e d}$ and $\mathbf{4} \boldsymbol{u}$-si-relaxed by 22.6 and $14.4 \mathrm{kcal} \mathrm{mol}^{-1}$, respectively, induced the styryl groups to adopt $\eta^{2}$ - and $\eta^{3}$ - coordination modes, respectively. Of the two products, the 2,1-down-re insertion product (4d-re-relaxed) is thermodynamically 
more stable (by $13.2 \mathrm{kcal} \mathrm{mol}^{-1}$ ) due to a lesser hindered orientation of the styryl phenyl ring pointing towards the less bulky $\mathrm{Cp}$ ring. The calculations confirm that the down mode is the preferred one, from a thermodynamic point of view.

ii) Second styrene insertion. Based on the above results, the second styrene insertion was computed only from the most stable product, i.e. 4d-re-relaxed, considering the four insertion modes mentioned earlier. Thus, energy profiles were computed for 2,1-down-re (6d-re) and 2,1-up-si (6u-si) stationary insertions and for 2,1-up-re (6u'-re) and 2,1-down-si (6d'-si) migratory insertions (Figure 4).

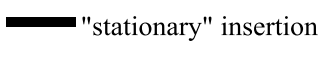

"migratory" insertion

$\uparrow \Delta \mathrm{H}\left(\mathrm{kcal} . \mathrm{mol}^{-1}\right)$

$\underset{\text { structure }}{\longrightarrow}$

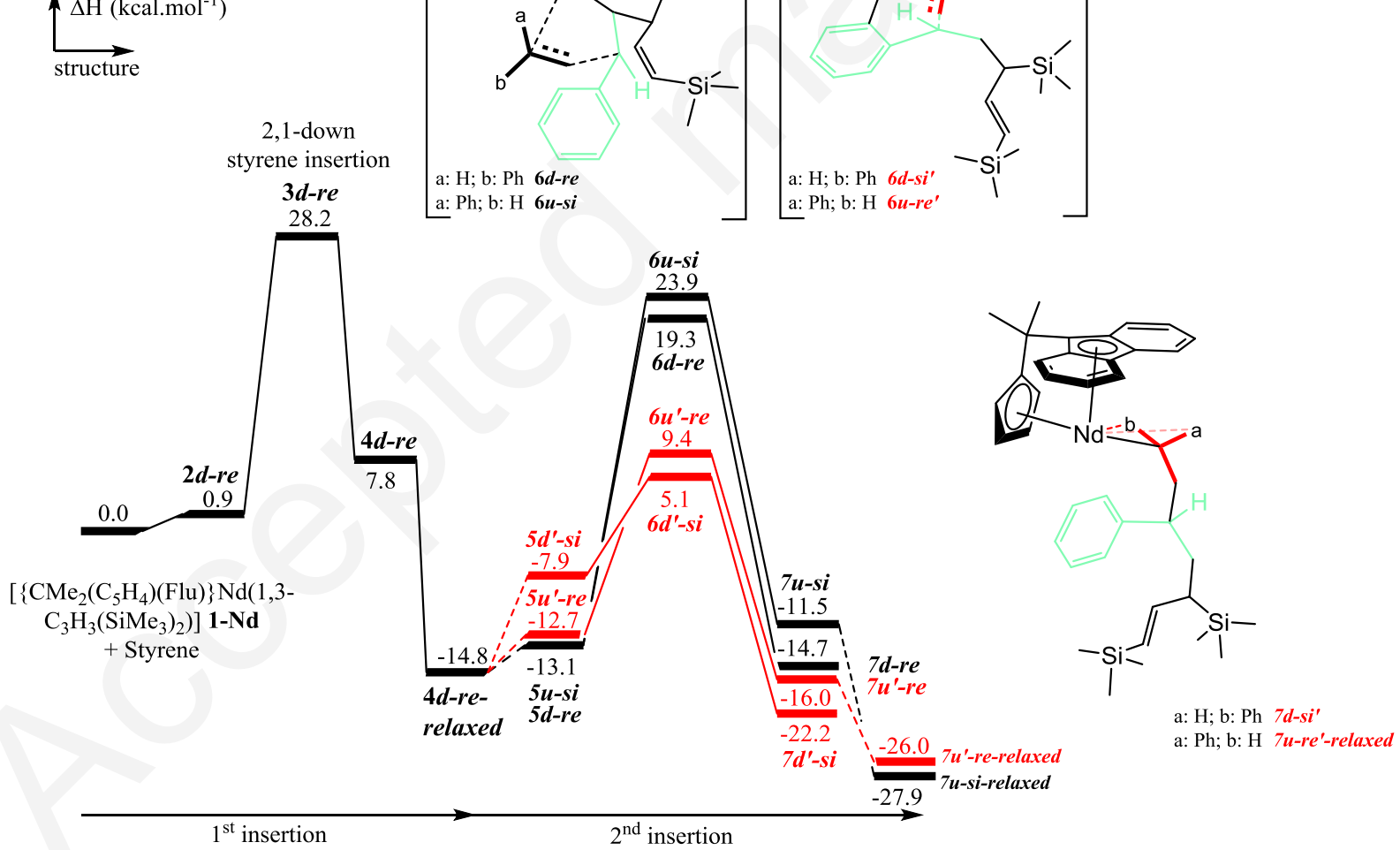

Figure 4. Energetic profiles for the first and second styrene insertions in $\left\{\mathrm{Me}_{2} \mathrm{C}\left(\mathrm{C}_{5} \mathrm{H}_{4}\right)(\mathrm{Flu})\right\} \mathrm{Nd}\left(1,3-\mathrm{C}_{3} \mathrm{H}_{3}\left(\mathrm{SiMe}_{3}\right)_{2}\right)(\mathbf{1 - N d})$. 
The migratory insertion mode is clearly the preferred one. This is evidenced from the significantly lower corresponding insertion barriers $\left(\Delta H^{\#}=19.9\right.$ and $\left.24.2 \mathrm{kcal} \mathrm{mol}^{-1}\right)$ as compared to those for the stationary insertion pathway $\left(\Delta H^{\#}=34.1\right.$ and $\left.38.7 \mathrm{kcal} \mathrm{mol}^{-1}\right)$. This results from repulsion between the Flu ligand and the $\mathrm{Me}_{3} \mathrm{Si}$ group of the allyl ligand (Figure S27) in the transition states of the stationary insertion mode, which does not exist for those for migratory insertion. For the migratory insertion pathway, the transition state $\mathbf{6} \boldsymbol{u}$ '-re is less stable (by $4.3 \mathrm{kcal} \mathrm{mol}^{-1}$ ) than $\mathbf{6} \boldsymbol{d}^{\prime}$-si due to the repulsion between the $\mathrm{Ph}$ ring of the last styryl moiety and the Flu ligand. Furthermore, in the structures of all transition states, the styryl group of the ultimate styrene unit is $\eta^{1}$-coordinated (and not $\eta^{2}$-), thus facilitating insertion of the second incoming styrene unit. The difference between the two migratory insertion barriers $\left(\boldsymbol{6} \boldsymbol{\boldsymbol { u } ^ { \prime }}\right.$-re/ $\left.\mathbf{6} \boldsymbol{d}^{\prime}-\mathbf{s i}=4.3 \mathrm{kcal} \mathrm{mol}^{-1}\right)$ is within the error range of the method and therefore the main product will be the thermodynamic one. As for the first insertion, a chain relaxation of the polymeryl chain in the products $\mathbf{7} \boldsymbol{u}^{\prime}$-re and $\mathbf{7 u}$-si afforded an extrastabilization by 10.0 and $16.4 \mathrm{kcal} \mathrm{mol}^{-1}$, respectively. Therefore, for the second insertion step, the 2,1-up-re insertion product $\mathbf{7 u}$ '-re-relaxed is more stable by $3.8 \mathrm{kcal} \mathrm{mol}^{-1}$ as compared to the 2,1-down-si insertion product $7 \boldsymbol{d}^{\text {'-si. }}$. This result could be attributed to the steric repulsion between the $\mathrm{Cp}$ ring and the $\mathrm{Ph}$ group of the last inserted styrene unit, leading to a destabilization of product $\mathbf{7 d}$ '-si (Figure S28). Thus, the calculations indicated the importance of the haptotropic shift (from $\eta^{3}$ to $\eta^{1}$ coordination mode) of the first inserted styryl unit ensuring the next monomers insertion. In addition, the insertion barrier differences

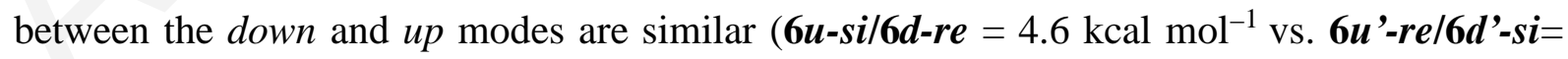
$4.3 \mathrm{kcal} \mathrm{mol}^{-1}$ ) and within the uncertainty of the method. Therefore, the results achieved so far suggest that second styrene insertion is mainly governed by thermodynamics (formation of the most stable product). 
The above results suggest that the early $\left(1^{\text {st }}\right.$ and $\left.2^{\text {nd }}\right)$ insertions in styrene polymerization with $\left\{\mathrm{Me}_{2} \mathrm{C}\left(\mathrm{C}_{5} \mathrm{H}_{4}\right)(\mathrm{Flu})\right\} \mathrm{Nd}\left(1,3-\mathrm{C}_{3} \mathrm{H}_{3}\left(\mathrm{SiMe}_{3}\right)_{2}\right)$ take place via a migratory mechanism. This is in striking contrast with the styrene insertion mechanism identified for $\left\{\mathrm{Me}_{2} \mathrm{C}\left(\mathrm{C}_{5} \mathrm{H}_{4}\right)(\mathrm{Flu})\right\} \mathrm{Nd}\left(\mathrm{C}_{3} \mathrm{H}_{5}\right)$ catalyst, for which stationary insertion mode is the most favorable one. This change in the insertion mode at the early stage of the polymerization results directly from the hindered allyl, which seeks to minimize steric repulsion caused by the bulky $\mathrm{SiMe}_{3}$ groups.

iii) Third styrene insertion. As suggested in the previous section, only insertions for the most stable product (7u'-re-relaxed) were considered for the third migratory insertion (Figure 5). The computed energy barriers are $21.1 \mathrm{kcal} \mathrm{mol}^{-1}$ for the 2,1-down-re insertion (9d-re) and $24.4 \mathrm{kcal} \mathrm{mol}^{-1}$ for the 2,1-up-si insertion (9u-si), affording an energy difference of $3.3 \mathrm{kcal}$ $\mathrm{mol}^{-1}$ depending on the phenyl ring orientation. This difference is smaller than the one

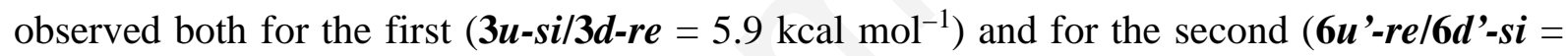
$4.3 \mathrm{kcal} \mathrm{mol}^{-1}$ ) insertions. Therefore, the syndioselectivity of polymerization cannot be due to kinetic but rather due to a thermodynamic control. Interestingly, for the third insertion, the corresponding barriers are lower than those calculated for the first insertion $\left(\Delta H^{\#}=21.1 \mathrm{kcal}\right.$ mol $^{-1}$ for 9 d-re vs. $\Delta H^{\#}=28.2 \mathrm{kcal} \mathrm{mol}^{-1}$ for $\mathbf{3 d}$-re , and $\Delta H^{\#}=24.4 \mathrm{kcal} \mathrm{mol}^{-1}$ for $\mathbf{9 u}$-si vs. $\Delta H^{\#}=34.1 \mathrm{kcal} \mathrm{mol}^{-1}$ for $\mathbf{3 u}$-si) and quite similar to those found for the second insertion (19.9 and $24.2 \mathrm{kcal} \mathrm{mol}^{-1}$ ) via migratory mechanism. This is in line with the decrease of the steric hindrance around the metal center upon increasing the length of the growing polymer chain. 


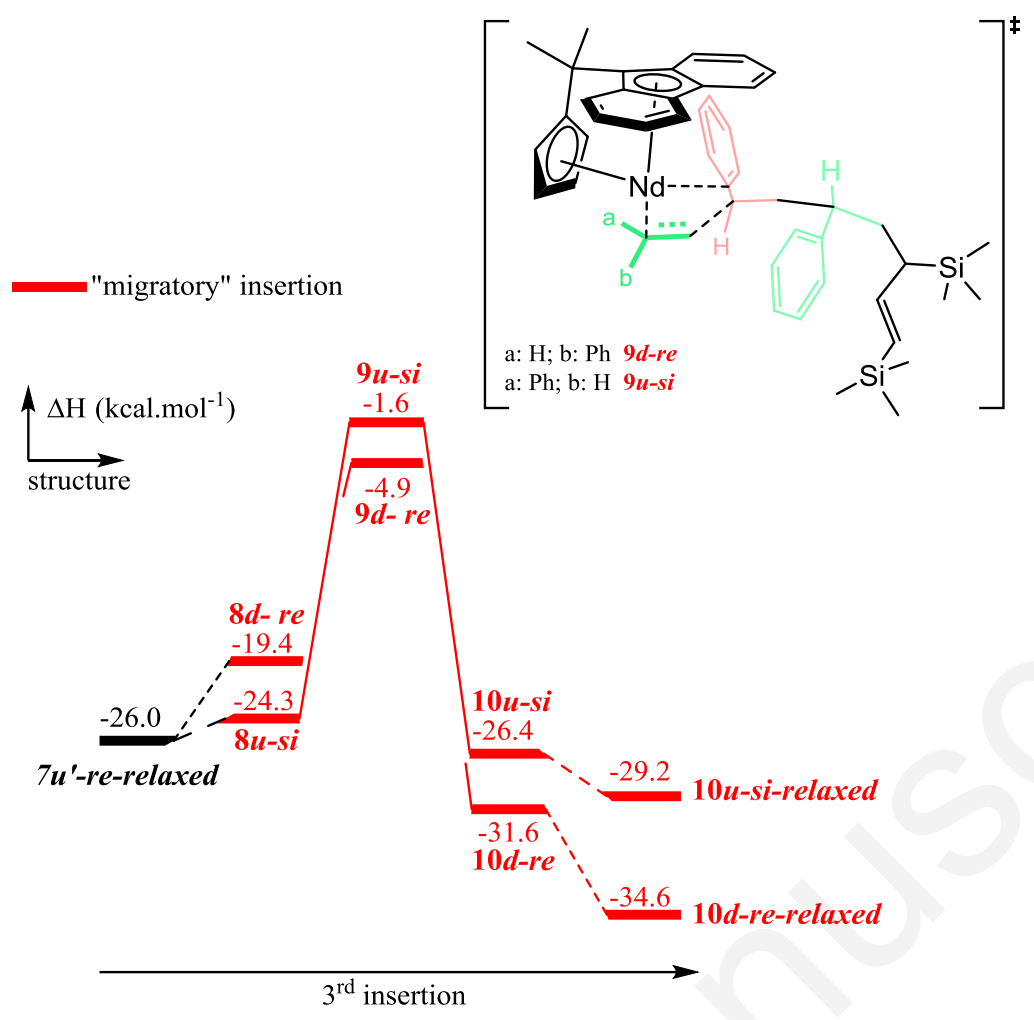

Figure 5. Energetic profile for the third styrene insertion in $\left\{\mathrm{Me}_{2} \mathrm{C}\left(\mathrm{C}_{5} \mathrm{H}_{4}\right)(\mathrm{Flu})\right\} \mathrm{Nd}(1,3-$ $\left.\mathrm{C}_{3} \mathrm{H}_{3}\left(\mathrm{SiMe}_{3}\right)_{2}\right)(\mathbf{1}-\mathbf{N d})$.

In order to explain these barrier differences, an electronic population analysis (NBO) was performed. The calculated charges on the styryl coordinated carbon atoms are $\left[\mathrm{C}^{2}\right.$ $(-0.40)$, ipso $(-0.13)$, ortho $(-0.35)]$ in $9 d-r e$, while for the allyl ligand are $\left[\mathrm{C}^{1}\right.$ (allyl) $(-0.88)$, $\mathrm{C}^{2}$ (allyl) (-0.28), $\mathrm{C}^{3}$ (allyl) (-0.89)] in $\mathbf{3 d - r e . ~ A s ~ i n ~ t h e ~ p r e v i o u s ~ c a s e , ~ c h a r g e s ~ i n ~} \mathbf{9 u - s i}$ are $\left[\mathrm{C}^{2}\right.$ $(-0.41)$, ipso $(-0.10)$, ortho $(-0.37)]$ and $(-0.90,-0.24,-0.92$, respectively) for the allyl moiety in $\mathbf{3 u}$-si. These results reveal that now, at the third insertion, the most nucleophilic carbon is the $\mathrm{C}^{2}$ one which is involved in the $\mathrm{C}-\mathrm{C}$ coupling (whereas it was on the $\mathrm{C}^{3}$ one for the first insertion). This confirms that the barrier variation is related to a charge localization effect which is implicitly associated with the steric hindrance.

As for the first insertion, the corresponding products obtained following the IRC of transitions states are alkyls $\mathbf{9 u}$-si and 9d-re. Further chain relaxation afforded the 
corresponding allylic products stabilized, by $2.8(\mathbf{1 0 u}$-si-relaxed $)$ and by $3.0 \mathrm{kcal} \mathrm{mol}^{-1}(\mathbf{1 0 d}$ re-relaxed). By analogy with the first insertion step, the 2,1-down-re insertion product 10dre-relaxed is more thermodynamically stable by $5.4 \mathrm{kcal} \mathrm{mol}^{-1}$ than the 2,1 -up-si insertion product 10u-si-relaxed. This difference of stability can be explained by a stabilizing $\pi$ interaction (between the $\mathrm{Ph}$ group of the second inserted styrene unit and the metal center) in 10d-re-relaxed compared to $10 u$-si-relaxed. In the latter product, it may also be noted the presence of a residual destabilizing repulsion between the Flu ring and the $\mathrm{SiMe}_{3}$ group which could have an effect on the stability of this product.

In terms of selectivity of the formed polymer chains, the results obtained computationally match the experiments as a sPS chain is predicted to result from this migratory polymerization mechanism. As already found for the unsubstituted allyl (see first section and reference 11), the tacticity is mainly controlled by thermodynamics, as the barrier differences are within the precision of the method (even if there is a slight kinetic preference for the syndiotactic enchainment for the even insertions). The factors that control this formation are the minimization of steric repulsion between the Flu ligand and the $\mathrm{Ph}$ ring of the incoming styrene, and the minimization of the one between the $\mathrm{Me}_{3} \mathrm{Si}$ group on the allyl and Flu ligands.

DFT investigation of styrene polymerization catalyzed by $\left\{\mathrm{Me}_{2} \mathrm{C}\left(\mathrm{C}_{5} \mathrm{H}_{4}\right)(2,7-\right.$ $\left.\left.t \mathrm{Bu}_{2} \mathrm{Flu}\right)\right\} N d\left(1,3-\mathrm{C}_{3} \mathrm{H}_{3}\left(\mathrm{SiMe}_{3}\right)_{2}\right) \quad(2-\mathrm{Nd}) \quad$ and $\quad\left\{\mathrm{Me}_{2} \mathrm{C}\left(\mathrm{C}_{5} \mathrm{H}_{4}\right)\left(3,6-t \mathrm{Bu} \mathrm{F}_{2} \mathrm{Flu}\right)\right\} N d(1,3-$ $\left.\mathrm{C}_{3} \mathrm{H}_{3}\left(\mathrm{SiMe}_{3}\right)_{2}\right)(5-\mathrm{Nd})$ - Effects of the fluorenyl substituents. As mentioned above, it was found experimentally that introduction of bulky substituents on the Flu moiety of catalyst may have a dramatic effect on styrene polymerization performance. Hence, 2-Nd that incorporates 2,7-t $\mathrm{Bu}_{2}$ groups in the Flu ligand exhibited good polymerization productivity and activity, whereas the 3,6- $t \mathrm{Bu}_{2}$-Flu substituted complex 5-Nd appeared to be completely inactive (vide supra). In order to obtain further insight into the effect of fluorenyl substitution, DFT 
calculations were performed for the first styrene insertion (according to 2,1-pathway) with 2Nd and 5-Nd (Figures 6 and 7, respectively).

For 2-Nd, both corresponding barriers are accessible from a kinetic point of view $\left(\Delta H^{\#}\right.$ $=29.3$ for $\mathbf{3 d}$-re and $29.6 \mathrm{kcal} \mathrm{mol}^{-1}$ for $\mathbf{3 u}$-si) and close to the one calculated for the unsubstituted system $\left\{\mathrm{Me}_{2} \mathrm{C}\left(\mathrm{C}_{5} \mathrm{H}_{4}\right)(\mathrm{Flu})\right\} \mathrm{Nd}\left(1,3-\mathrm{C}_{3} \mathrm{H}_{3}\left(\mathrm{SiMe}_{3}\right)_{2}\right)(\mathbf{1 - N d})$, i.e. for $\mathbf{3 d}-\boldsymbol{r e}\left(\Delta H^{\#}=\right.$ $28.2 \mathrm{kcal} \mathrm{mol}^{-1}$ ). The structure of transition state $\mathbf{3} \boldsymbol{u}$-si shows a change of coordination of the allyl ligand towards an $\eta^{1}$-mode $\left(\mathrm{Nd}-\mathrm{C}^{1}(\right.$ allyl $\left.)=2.80 \AA\right)$, thus minimizing steric repulsion between the $t \mathrm{Bu}$ and the $\mathrm{Me}_{3} \mathrm{Si}$ groups (Figure S31). This modification leads to a stabilization of $\mathbf{3 u}$-si by $6.8 \mathrm{kcal} \mathrm{mol}^{-1}$ with respect to the one of the unsubstituted system $\mathbf{1 - N d}\left(\Delta H^{\#}=\right.$ $34.1 \mathrm{kcal} \mathrm{mol}^{-1}$ ). For $\mathbf{3 d - r e}$, there is repulsion between the $t \mathrm{Bu}$ substituents and the $\mathrm{Ph}$ group of the incoming styrene.

Regarding the products, there is again no selectivity between the two modes $\mathbf{4 u}$-si/4dre-relaxed as the energy difference is only $0.8 \mathrm{kcal} \mathrm{mol}^{-1}$ (while it was $13.2 \mathrm{kcal} \mathrm{mol}^{-1}$ for $\mathbf{1 -}$ $\mathbf{N d ) . ~ I n d e e d , ~ c h a i n ~ r e l a x a t i o n ~ i n ~ p r o d u c t ~} \mathbf{4} \boldsymbol{u}$-si decreases the steric repulsion between the Flu moiety and the $\mathrm{Me}_{3} \mathrm{Si}$ group of the allyl ligand. In addition, this structure has a $\pi-\pi$ interaction between the $\mathrm{Ph}$ ring of the inserted styrene unit and the 6-membered ring of the Flu ligand. This tends to stabilize product $4 \boldsymbol{u}$-si by $5.9 \mathrm{kcal} \mathrm{mol}^{-1}$ as compared with the same insertion product for 1-Nd. Product 4d-re-relaxed is destabilized by $6.5 \mathrm{kcal} \mathrm{mol}^{-1}$ which could arise from a repulsion between the $t \mathrm{Bu}$ group on the Flu moiety and the $\mathrm{Me}_{3} \mathrm{Si}$ group on the allyl ligand. 

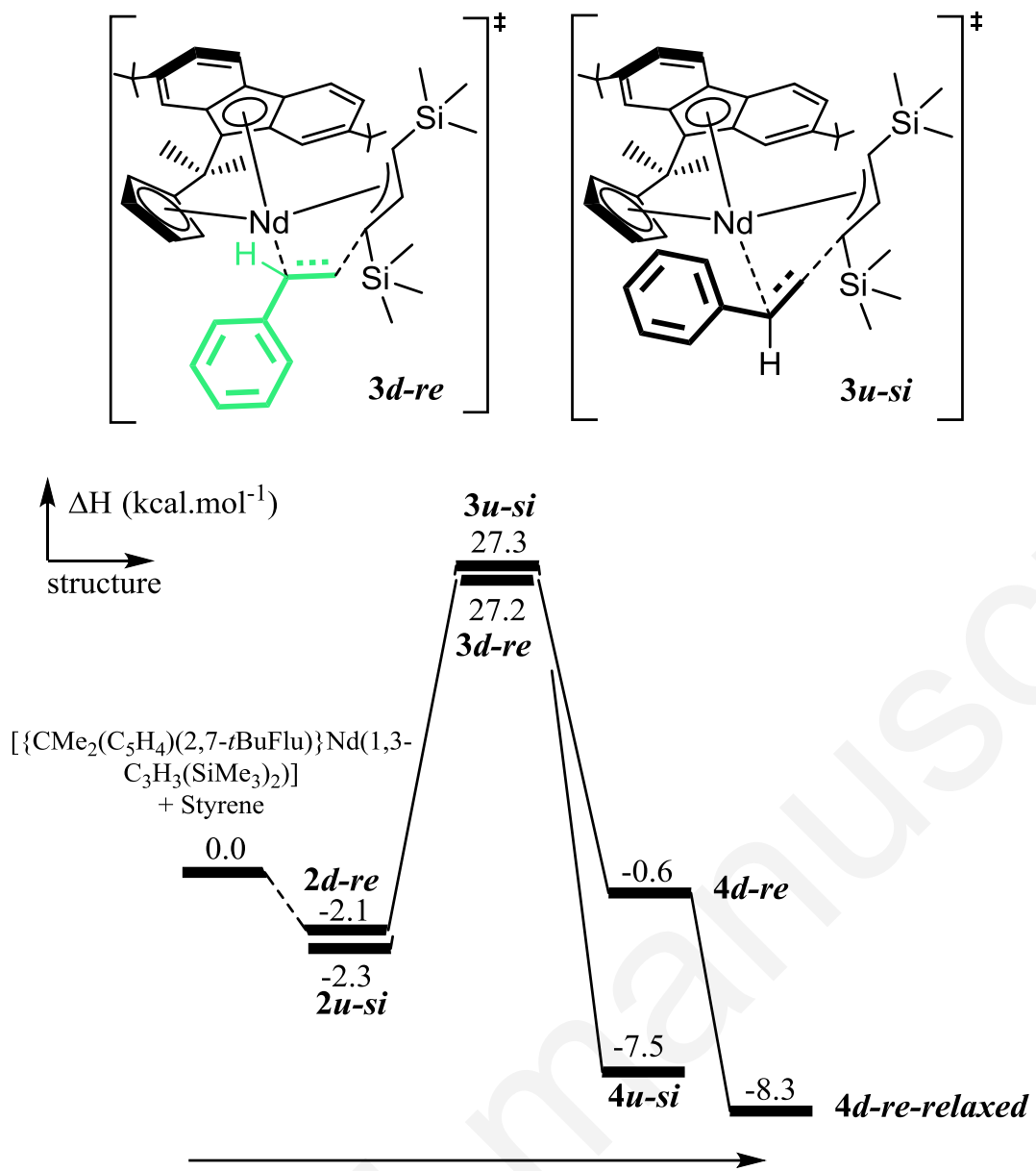

Figure 6. Energetic profiles for the first styrene insertion in $\left\{\mathrm{Me}_{2} \mathrm{C}\left(\mathrm{C}_{5} \mathrm{H}_{4}\right)(2,7-\right.$ $\left.\left.t \mathrm{Bu}_{2} \mathrm{Flu}\right)\right\} \mathrm{Nd}\left(1,3-\mathrm{C}_{3} \mathrm{H}_{3}\left(\mathrm{SiMe}_{3}\right)_{2}\right)(\mathbf{2}-\mathbf{N d})$.

For 5-Nd, the activation barriers are also close to those obtained for unsubstituted complex 1-Nd $\left(\Delta H^{\#}=28.1\right.$ vs. $28.2 \mathrm{kcal} \mathrm{mol}^{-1}$ for $\mathbf{3 d - r e}$ and 35.4 vs. $34.1 \mathrm{kcal} \mathrm{mol}^{-1}$ for $\mathbf{3 u}$ si). This is reflected in the transition state structures which are similar to those for 1-Nd (Figure S33). A priori, from the kinetics point of view, the insertion of styrene is still possible. However, formation of both insertion products is endothermic (by 6.3 and $14.9 \mathrm{kcal}$ $\mathrm{mol}^{-1}$, respectively) due to the steric hindrance imposed by the growing polymer chain, therefore these structures cannot adopt allylic forms (Figure S34). The steric hindrance suggests that the barrier will be high to obtain the relaxed products, even if they are 
thermodynamically favorable (by $-10.1 \mathrm{kcal} \mathrm{mol}^{-1}$ for $\mathbf{4 d - r e - r e l a x e d}$ and $-12.5 \mathrm{kcal} \mathrm{mol}^{-1}$ for 4u-si-relaxed).

Hence, the formal de-insertion reaction is more favorable $\left(\Delta H^{\#}=21.8\right.$ for $\mathbf{3 d}$-re and $20.5 \mathrm{kcal}$ $\mathrm{mol}^{-1}$ for $\mathbf{3 u}$-si) than the insertion reaction. This finding matches the experimentally observed complete inactivity of system $\mathbf{5 - N d}$.
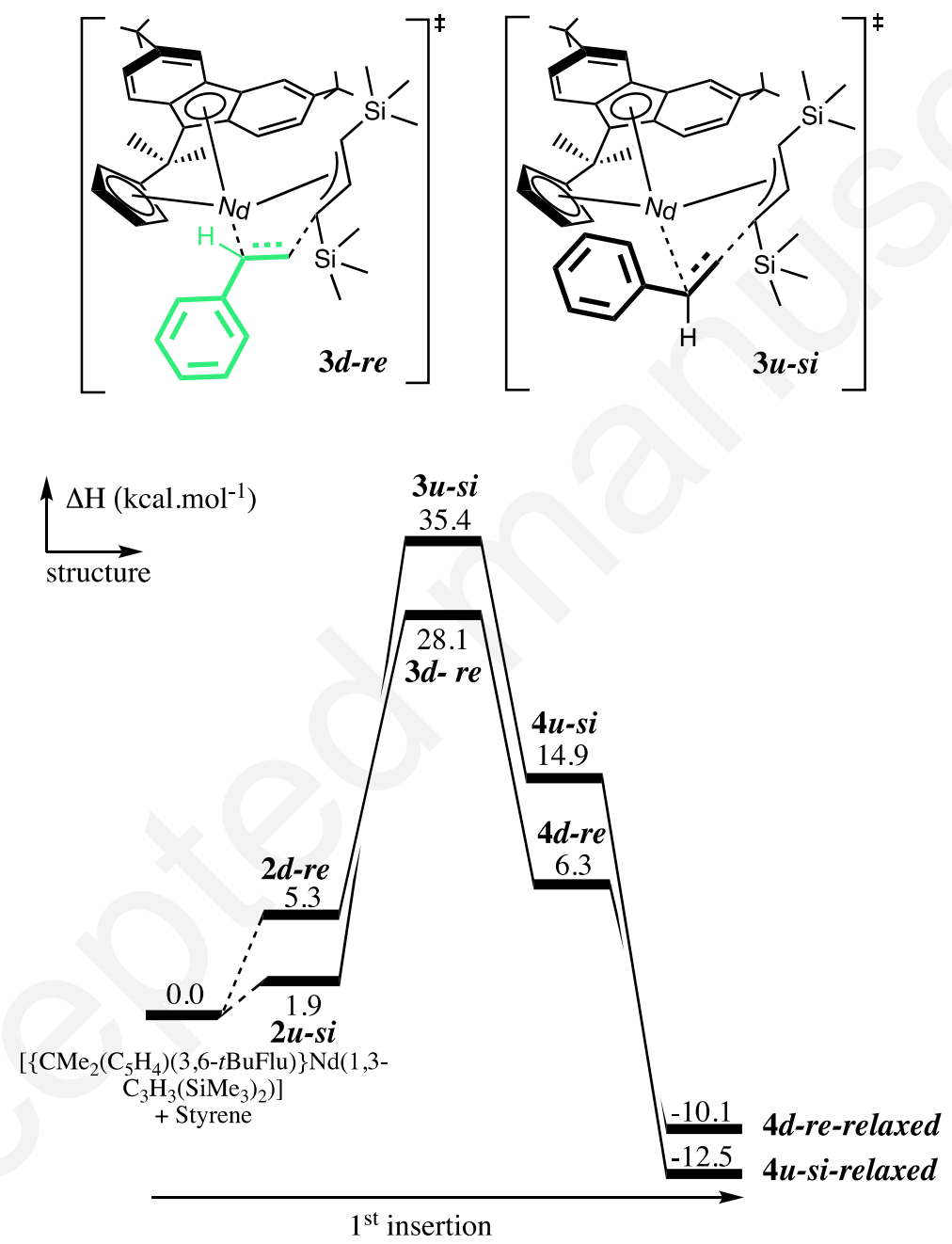

Figure 7. Energetic profiles for the first styrene insertion in $\left[\left\{\mathrm{CMe}_{2}\left(\mathrm{C}_{5} \mathrm{H}_{4}\right)(3,6-\right.\right.$ $\left.\left.\left.t \mathrm{Bu}_{2} \mathrm{Flu}\right)\right\} \mathrm{Nd}\left(1,3-\mathrm{C}_{3} \mathrm{H}_{3}\left(\mathrm{SiMe}_{3}\right)_{2}\right)\right](\mathbf{5}-\mathbf{N d})$.

In summary, these calculations show that substituents on the Flu moiety have little or no influence on the activation barriers. Indeed, in the corresponding transition states for 
insertions, the allyl ligands adopt various configurations (supine in $\mathbf{1 - N d}$ and $\mathbf{5 - N d}$ and prone in 2-Nd, with respect to the Flu ligand), thus minimizing repulsions between the $t \mathrm{Bu}$ and the $\mathrm{Me}_{3} \mathrm{Si}$ groups. Rather, this substitution has an influence on the coordination of monomer leading to destabilization of the corresponding adducts $\left(\Delta H_{\text {coord }}=5.3\right.$ and $1.9 \mathrm{kcal} \mathrm{mol}^{-1}$ in $\mathbf{5}$ Nd vs. -2.1 and $-2.3 \mathrm{kcal} \mathrm{mol}^{-1}$ in $\mathbf{2 - N d}$ vs. $0.9 \mathrm{kcal} \mathrm{mol}^{-1}$ in $\mathbf{1 - N d}$ ) and affecting the stability of product in case of 5-Nd. Basically, these computations demonstrate that the 2,7-tBu 2 substitution makes the system less selective as the prototype one 1-Nd for the first insertion, while the 3,6- $t \mathrm{Bu}_{2}$ substitution simply makes the system inactive.

\section{Conclusions}

A series of group 3 ansa-lanthanidocene allyl complexes incorporating \{RRC-(R'R'Flu $(\mathrm{Cp})\}^{2-}$ ligands was synthesized. The activity of these single-component systems in styrene polymerization was found to be dependent on the substitution at both the bridge and fluorenyl moieties. Complexes 1-Nd-K(allyl), 2-Nd, 4-Nd, 6-Nd and 7-Nd afforded active and stereoselective catalytic systems (especially 2-Nd), whereas 3-Nd and 5-Nd are completely inactive. The presence of $t \mathrm{Bu}$ substituents at 3,6- positions on the fluorenyl moiety causes a dramatic decrease of the productivity, due to steric hindrance that hampers styrene coordination/insertion. The activity of complexes 2-Sc, 2-Y, 2-La, 2-Nd, 2-Sm and 2-Pr was found in the following order $\mathrm{Nd} \approx \mathrm{Pr}>\mathrm{La} \approx \mathrm{Sm}>>\mathrm{Y}>\mathrm{Sc}$. Within the whole series, 2-Nd and 2-Pr demonstrated the highest productivities (maximum of ca. 4,500 $\mathrm{kg} \cdot \mathrm{mol}^{-1} \cdot \mathrm{h}^{-1}$ at $120{ }^{\circ} \mathrm{C}$ in bulk at $\left.[\mathrm{St}] /[\mathrm{Nd}]=76,000\right)$ and a high syndioselectivity $\left([r]^{5}=\right.$ $71-78 \%)$

The theoretical investigations highlighted that production of sPS occurs according to a migratory polymerization mechanism, which is directly related to the repulsion induced by the bulky groups on the allyl moiety. The stereoselectivity is controlled by thermodynamics 
through minimization of repulsions between styrene phenyl ring/fluorenyl and fluorenyl/SiMe 3 substituents of the allyl ligand (for the initiation step). The calculations confirmed that the presence of $t \mathrm{Bu}$ substituents on the fluorenyl moiety has a dramatic effect. The growing polymer chain is hindered and may (2-Nd) or may not (5-Nd) relax to provide a thermodynamically favorable product.

\section{Experimental Section}

General considerations. All experiments were performed under a dry argon atmosphere, using a glovebox or standard Schlenk techniques. THF and $\mathrm{Et}_{2} \mathrm{O}$ were distillated prior to use from sodium benzophenone ketyl. Heptane, cyclohexane and dodecane were distillated from $\mathrm{CaH}_{2}$ and stored on $3 \AA$ Á molecular sieves. Deuterated solvents (benzene- $d_{6}, \mathrm{THF}-d_{8} ;>99.5 \%$ D; Euriso-top) were distillated from $\mathrm{Na} / \mathrm{K}$ alloy or $\mathrm{CaH}_{2}$ and stored on $3 \AA$ Á molecular sieves. $\mathrm{CDCl}_{3}(99.8 \% \mathrm{D}$, Euriso-top) was used as received. 2,7- and 3,6-Di-tert-butyl-fluorenes were generously provided by Total Raffinage-Chimie. 5-(Propan-2-ylidene)cyclopenta-1,3diene, ${ }^{49}$ 2,7-dicumylfluorene, ${ }^{34}$ 2,7-bis(1,1-diphenylethyl)fluorene, ${ }^{20} \mathrm{Me}_{2} \mathrm{C}\left(\mathrm{C}_{5} \mathrm{H}_{5}\right)(\mathrm{FluH})$

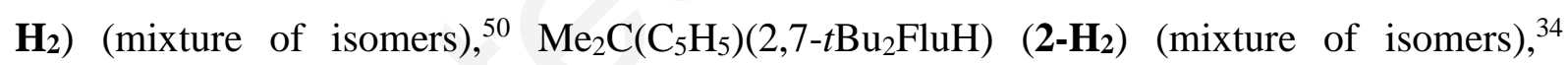
$\mathrm{Me}_{2} \mathrm{C}\left(\mathrm{C}_{5} \mathrm{H}_{5}\right)\left(\mathrm{Oct}_{2} \mathrm{FluH}\right)\left(\mathbf{3}-\mathrm{H}_{2}\right)$ (mixture of isomers), ${ }^{33} \mathrm{Ph}_{2} \mathrm{C}\left(\mathrm{C}_{5} \mathrm{H}_{5}\right)(\mathrm{FluH})\left(\mathbf{4}-\mathbf{H}_{2}\right),{ }^{\text {Erreur } \text { ! Signet }}$ non défini. $\mathrm{Me}_{2} \mathrm{C}\left(\mathrm{C}_{5} \mathrm{H}_{5}\right)\left(3,6-t \mathrm{Bu}_{2} \mathrm{FluH}\right) \quad\left(\mathbf{5}-\mathrm{H}_{2}\right)$ (mixture of isomers), ${ }^{51} \mathrm{Me}_{2} \mathrm{C}\left(\mathrm{C}_{5} \mathrm{H}_{5}\right)(2,7-$ dicumylFluH) (6-- $\left.\mathbf{H}_{2}\right)$ (mixture of isomers), ${ }^{34}$ and $\left[\mathrm{Me}_{2} \mathrm{C}\left(\mathrm{C}_{5} \mathrm{H}_{4}\right)(\mathrm{Flu})\right] \mathrm{Nd}\left(\mathrm{C}_{3} \mathrm{H}_{5}\right)(\mathrm{THF})$ $\mathbf{N d}(\mathbf{a l l}))^{8}$ were prepared following protocols published in the literature. THF-adducts $\mathrm{YCl}_{3}(\mathrm{THF})_{3.5}$ and $\mathrm{ScCl}_{3}(\mathrm{THF})_{3}$ were obtained after continuous extraction of the corresponding anhydrous chlorides (Strem Chemicals). $\mathrm{LaCl}_{3}, \mathrm{SmCl}_{3}$ and $\mathrm{PrCl}_{3}$ were used as received (anhydrous, $99.9 \% \mathrm{Ln}$, Strem Chemicals). $\mathrm{NdCl}_{3}(\mathrm{THF})_{2}$ was provided by Rhodia. Styrene (Fisher Chemical, general purpose grade, stabilized with 10-15 ppm of tertbutylcatechol) was eluted through neutral aluminum oxide, stirred and heated over $\mathrm{CaH}_{2}$, then 
vacuum-distilled and stored over $3 \AA \AA$ molecular sieves at $-30{ }^{\circ} \mathrm{C}$ under $\operatorname{argon} .(n \mathrm{Bu})_{2} \mathrm{Mg}$ solution (1.0 M in heptane, Sigma-Aldrich) was used as received.

Instruments and measurements. NMR spectra of air- and moisture- sensitive compounds were recorded on Bruker AM-400 and AM-500 spectrometers in Teflon-valved NMR tubes at room temperature. ${ }^{1} \mathrm{H}$ and ${ }^{13} \mathrm{C}$ chemical shifts are reported in ppm vs. $\mathrm{SiMe}_{4}$ and were determined using residual solvent signal. Coupling constants are given in Hertz. Assignments of signals were carried out using 1D $\left({ }^{1} \mathrm{H},{ }^{13} \mathrm{C}\left\{{ }^{1} \mathrm{H}\right\}\right.$, JMOD) and 2D (COSY, HMBC, HMQC) NMR experiments. Elemental analyses were performed on a Carlo Erba 1108 Elemental Analyzer instrument at the London Metropolitan University by Stephen Boyer and were the average of a minimum of two independent measurements. In most cases, despite repeated attempts on different batches of each of these compounds (including for crystals of 1-Nd-K(allyl), 2-La, 2-Pr, 2-Nd, 2-Sm and 4-Nd which were also characterized by XRD), we were unable to obtain satisfactory and reproducible elemental analyses for these compounds; systematically, the analyses returned low $\mathrm{C}$ contents $(<2-6 \%)$. As reported in several other instances, this can most likely be attributed to the presence of substantial amounts of silicon in the samples leading to the formation of non-pyrolisable silicon carbides. ${ }^{52,53}$

${ }^{13} \mathrm{C}\left\{{ }^{1} \mathrm{H}\right\}$ NMR and GPC analyses of sPS samples were performed in the research center of Total Raffinage-Chimie in Feluy (Belgium). These ${ }^{13} \mathrm{C}\left\{{ }^{1} \mathrm{H}\right\}$ NMR analyses were run on a Bruker Avance III $500 \mathrm{MHz}$ with a cryoprobe HTDUL 10mm (trichlorobenzene/ $\mathrm{C}_{6} \mathrm{D}_{6}(2 \mathrm{~mL} / 0.5 \mathrm{~mL})$ ). The GPC analyses were performed in 1,2,4trichlorobenzene at $135{ }^{\circ} \mathrm{C}$ using PS standards for calibration. Differential scanning calorimetry (DSC) analyses were performed on a Setaram DSC 131 apparatus, under continuous flow of helium and using aluminum capsules. Crystallization temperatures were 
measured during the first cooling $\left(10^{\circ} \mathrm{C} \cdot \mathrm{min}^{-1}\right)$, and glass transition and melting temperatures were measured during the second heating $\left(10^{\circ} \mathrm{C} \cdot \mathrm{min}^{-1}\right)$.

$\mathrm{Me}_{2} \mathrm{C}\left(\mathrm{C}_{5} \mathrm{H}_{5}\right)(2,7-b i s(1,1-d i p h e n y l e t h y l) F l u H)$ (7-H2) (mixture of isomers). To a solution of 2,7-bis(1,1-diphenylethyl)Flu (1.30 g, $2.4 \mathrm{mmol})$ in THF was added under vigorous stirring $n \mathrm{BuLi}$ (1.1 $\mathrm{mL}$ of a $2.5 \mathrm{M}$ solution in hexane, $2.7 \mathrm{mmol}, 1.1$ equiv). The solution turned deep red and was stirred overnight at room temperature. Dimethylfulvene (0.40 mL, $3.2 \mathrm{mmol}, 1.3$ equiv) was added dropwise at $0{ }^{\circ} \mathrm{C}$ and the mixture was stirred overnight at room temperature. After careful hydrolysis with excess water $(150 \mathrm{~mL})$, extraction by $\mathrm{Et}_{2} \mathrm{O}(2 \times 100 \mathrm{~mL})$, drying the ether extracts over magnesium sulfate and

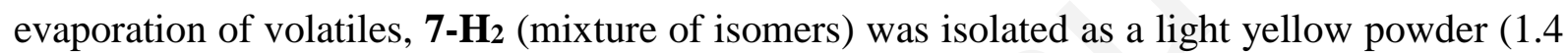
g, 90\%). ${ }^{1} \mathrm{H} \mathrm{NMR}\left(\mathrm{CDCl}_{3}, 400 \mathrm{MHz}, 25^{\circ} \mathrm{C}\right): \delta 7.56\left(\mathrm{~d}, J_{\mathrm{H}-\mathrm{H}}=8.2,2 \mathrm{H},(\mathrm{C}-4) H\right.$ and $(\mathrm{C}-5) H$, Flu), 7.31-6.91 (m, 24H, overlapped with the signal from residual $\mathrm{CHCl}_{3}, \mathrm{Ph}$ and $\mathrm{Flu}$ ), 6.72-5.66 (m, 3H, CH, Cp), 4.04, 3.98 (s, 1H, (C-9)H, Flu), 2.93, 2.55 (s, 2H, CH2, Cp), 2.18 (s, 6H, MePh $2 \mathrm{C}-), 0.93$ (s, 6H, $\left.\left(\mathrm{CH}_{3}\right)_{2} \mathrm{C}-\right) .{ }^{13} \mathrm{C}\left\{{ }^{1} \mathrm{H}\right\} \mathrm{NMR}\left(\mathrm{CDCl}_{3}, 100 \mathrm{MHz}, 25{ }^{\circ} \mathrm{C}\right): \delta 157.17$ $\left(\mathrm{C}_{\text {quat }}, \mathrm{Cp}\right), 154.90$ ( $\left.\mathrm{C}_{\text {quat }}, \mathrm{Flu}\right), 149.56,149.51,149.49,149.41\left(\mathrm{C}_{\text {quat }}, \mathrm{Ph}\right), 147.07,147.02$ ( $\mathrm{C}_{\text {quat }}, \mathrm{C}-2$ and C-7, Flu), 145.50 ( $\left.\mathrm{C}_{\text {quat }}, \mathrm{Flu}\right), 139.78,139.72\left(\mathrm{C}_{\text {quat }}, \mathrm{Flu}\right), 134.38(\mathrm{CH}, \mathrm{Cp})$, $132.81(C H, C p), 132.14(C H, C p), 130.74(C H, C p), 128.90(C H, P h), 127.94,127.92(C H$, Ph), 127.63 (CH, Flu), 127.02 (CH, Flu), 126.01, 125.99 (CH, Ph), $125.00(C H, C p), 118.53$, $118.51\left(\mathrm{CH}, \mathrm{C}-4\right.$ and C-5, Flu), 57.97, 55.71 (CH, C-9, Flu), 52.77, 52.75 (Cquat, $\mathrm{MePh}_{2} \mathrm{C}-$ ), 40.75, 40.71, $40.54\left(\mathrm{CH}_{2}, \mathrm{Cp}\right), 39.70$ ( $\mathrm{C}_{\text {quat }}, \mathrm{Me}_{2} \mathrm{C}$-), 30.76, $30.73\left(\mathrm{CH}_{3}, M e \mathrm{Ph}_{2} \mathrm{C}-\right), 25.75$, $24.53\left(\mathrm{CH}_{3}, \mathrm{Me}_{2} \mathrm{C}-\right)$.

$\left[\mathrm{Me}_{2} \mathrm{C}\left(\mathrm{C}_{5} \mathrm{H}_{4}\right)\left(2,7-t \mathrm{Bu}_{2} \mathrm{Flu}\right)\right] \mathbf{Y}\left(\mathbf{1}, 3-\mathrm{C}_{3} \mathbf{H}_{3}\left(\mathrm{SiMe}_{3}\right)_{2}\right)$ (2-Y). Pro-ligand 2-H2 (0.20 g, $0.52 \mathrm{mmol})$ and $\mathrm{PhCH}_{2} \mathrm{~K}(0.14 \mathrm{~g}, 1.1 \mathrm{mmol}, 2.1$ equiv) in THF (40 mL) were stirred overnight at $50{ }^{\circ} \mathrm{C}$. The solution turned red-pink. Volatiles were removed under vacuum to give a red-pink powder. To the latter solid residue were added $\mathrm{YCl}_{3}(\mathrm{THF})_{3.5}(0.23 \mathrm{~g}, 0.52$ 
mmol, 1.0 equiv) and [1,3- $\left.\mathrm{C}_{3} \mathrm{H}_{3}\left(\mathrm{SiMe}_{3}\right)_{2}\right] \mathrm{K}(0.14 \mathrm{~g}, 0.62 \mathrm{mmol}, 1.2$ equiv $)$ in $\mathrm{Et}_{2} \mathrm{O}(20 \mathrm{~mL})$. The mixture was stirred overnight at room temperature. The resulting suspension was decanted and filtered to remove insoluble materials. Volatiles were removed under vacuum to give a yellow powder $(0.24 \mathrm{~g}, 71 \%) .{ }^{1} \mathrm{H}$ NMR $\left(\mathrm{C}_{6} \mathrm{D}_{6}, 500 \mathrm{MHz}, 25{ }^{\circ} \mathrm{C}\right): \delta 8.01-7.98(\mathrm{~m}, 4 \mathrm{H}$, Flu $), 7.13\left(\mathrm{dd}, J_{\mathrm{H}-\mathrm{H}}=8.7\right.$ and $\left.1.4,2 \mathrm{H}, \mathrm{Flu}\right), 7.03\left(\mathrm{td}, J_{\mathrm{H}-\mathrm{H}}=16.2\right.$ and $1.7,1 \mathrm{H}$, $\left.\left(\mathrm{Me}_{3} \mathrm{Si}\right) \mathrm{CHCHCH}\left(\mathrm{SiMe}_{3}\right)\right), 6.29\left(\mathrm{t}, J_{\mathrm{H}-\mathrm{H}}=2.6,2 \mathrm{H}, \mathrm{Cp}\right), 5.67\left(\mathrm{t}, J_{\mathrm{H}-\mathrm{H}}=2.6,2 \mathrm{H}, \mathrm{Cp}\right)$, 2.41-2.37 (m, $6 \mathrm{H}+2 \mathrm{H}$, overlapped signals from $\left(\mathrm{CH}_{3}\right)_{2} \mathrm{C}-$ and $\left.\left(\mathrm{Me}_{3} \mathrm{Si}\right) \mathrm{CHCHCH}\left(\mathrm{SiMe}_{3}\right)\right)$, $1.36(\mathrm{~s}, 18 \mathrm{H}, t \mathrm{Bu}),-0.10\left(\mathrm{~s}, 18 \mathrm{H}, \mathrm{Si} M e_{3}\right) .{ }^{13} \mathrm{C}\left\{{ }^{1} \mathrm{H}\right\}$ NMR $\left(\mathrm{C}_{6} \mathrm{D}_{6}, 125 \mathrm{MHz}, 25^{\circ} \mathrm{C}\right): \delta 163.7$ (( $\left.\mathrm{Me}_{3} \mathrm{Si}\right) \mathrm{CHCHCH}\left(\mathrm{SiMe}_{3}\right)$ ), 150.1 (quat.C, $t \mathrm{Bu}-C(\mathrm{Flu})$ ), 128.1 (quat.C, $\mathrm{Cp}$ ), 126.3 (quat.C, Flu), 123.5 ( $\mathrm{CH}$, Flu), $118.4(\mathrm{CH}, \mathrm{Flu}), 118.3$ (quat.C, Flu), 116.6 (C-1 and C-8, Flu), 111.3 (Cp), 104.9 (Cp), 93.7 (C-9, Flu), 87.6 (( $\left.\mathrm{Me}_{3} \mathrm{Si}\right) \mathrm{CHCHCH}\left(\mathrm{SiMe}_{3}\right)$ ), 42.5 (quat.C, $\left.\left(\mathrm{CH}_{3}\right)_{2} \mathrm{C}\right)$, 36.1 (quat.C, $\left(\mathrm{CH}_{3}\right)_{3} \mathrm{C}$-Flu), $32.2\left(\left(\mathrm{CH}_{3}\right)_{3} \mathrm{C}-\mathrm{Flu}\right), 30.7\left(\left(\mathrm{CH}_{3}\right)_{2} \mathrm{C}-\right), 1.5(\mathrm{SiMe})_{3}$. Anal. Calcd for $\mathrm{C}_{38} \mathrm{H}_{55} \mathrm{Si}_{2} \mathrm{Y}$ (656.94): C, 69.48; H, 8.44. Typical analyses returned low C contents (Found: C, 66.65; H, 8.20).

$\left\{\left[\mathrm{Me}_{2} \mathrm{C}\left(\mathrm{C}_{5} \mathrm{H}_{4}\right)\left(3,6-t \mathrm{Bu}_{2} \mathrm{Flu}\right)\right]_{2} \mathrm{Nd}\left(1,3-\mathrm{C}_{3} \mathrm{H}_{3}\left(\mathrm{SiMe}_{3}\right)_{2}\right\}^{-} \mathrm{K}^{+}(1-\mathrm{Nd}-\mathrm{K}(\mathrm{allyl})) . \quad\right.$ Using a protocol similar to that described above for 2-Y, 1-Nd-K(allyl)was prepared from 1-H2 $(0.25$ g, $0.92 \mathrm{mmol}), \mathrm{PhCH}_{2} \mathrm{~K}\left(0.25 \mathrm{~g}, 1.9 \mathrm{mmol}, 2.1\right.$ equiv), $\mathrm{NdCl}_{3}(\mathrm{THF})_{2}(0.36 \mathrm{~g}, 0.91 \mathrm{mmol}, 1.0$ equiv) and $\left[1,3-\mathrm{C}_{3} \mathrm{H}_{3}\left(\mathrm{SiMe}_{3}\right)_{2}\right] \mathrm{K}(0.21 \mathrm{~g}, 0.91 \mathrm{mmol}, 1.0$ equiv). 1-Nd-K(allyl) was isolated as a deep red crystalline powder $(0.17 \mathrm{~g}, 22 \%)$. Single crystals of 1-Nd-K(allyl) suitable for X-ray diffraction analysis were grown from a toluene solution at room temperature. No satisfactory elemental analyses could be obtained, even on recrystallized material.

$\left[\mathrm{Me}_{2} \mathrm{C}\left(\mathrm{C}_{5} \mathrm{H}_{4}\right)\left(2,7-t \mathrm{Bu}_{2} \mathrm{Flu}\right)\right] \mathbf{N d}\left(\mathbf{1}, 3-\mathrm{C}_{3} \mathrm{H}_{3}\left(\mathrm{SiMe}_{3}\right)_{2}\right)(\mathrm{THF})$ (2-Nd). Using a protocol similar to the one described above for 2-Y, 2-Nd was prepared from $\mathbf{2}-\mathbf{H}_{2}(1.00 \mathrm{~g}, 2.6 \mathrm{mmol})$, $\mathrm{PhCH}_{2} \mathrm{~K}\left(0.71 \mathrm{~g}, 5.5 \mathrm{mmol}, 2.1\right.$ equiv), $\mathrm{NdCl}_{3}(\mathrm{THF})_{2}(1.03 \mathrm{~g}, 2.6 \mathrm{mmol}, 1.0$ equiv) and [1,3$\left.\mathrm{C}_{3} \mathrm{H}_{3}\left(\mathrm{SiMe}_{3}\right)_{2}\right] \mathrm{K}(0.58 \mathrm{~g}, 2.6 \mathrm{mmol}, 1.0$ equiv). 2-Nd was isolated as a brownish-green 
powder $(0.51 \mathrm{~g}, 25 \%)$. Single crystals of 2-Nd suitable for X-ray diffraction analysis were grown from an heptane solution at $-30{ }^{\circ} \mathrm{C}$. No satisfactory elemental analyses could be obtained, even on recrystallized material.

$\left[\mathrm{Me}_{2} \mathrm{C}\left(\mathrm{C}_{5} \mathrm{H}_{4}\right)\left(\mathrm{Oct}_{2} \mathrm{Flu}\right)\right] \mathbf{N d}\left(\mathbf{1}, 3-\mathrm{C}_{3} \mathrm{H}_{3}\left(\mathrm{SiMe}_{2}\right)_{2}\right)(\mathrm{THF}) \quad(3-\mathrm{Nd}) . \quad$ Using a protocol similar to that described above for 2-Y, 3-Nd was prepared from 3-H2 $(0.20 \mathrm{~g}, 0.41 \mathrm{mmol})$, $\mathrm{PhCH}_{2} \mathrm{~K}\left(0.11 \mathrm{~g}, 0.85 \mathrm{mmol}, 2.1\right.$ equiv), $\mathrm{NdCl}_{3}(\mathrm{THF})_{2}(0.16 \mathrm{~g}, 0.41 \mathrm{mmol}, 1.0$ equiv) and [1,3- $\left.\mathrm{C}_{3} \mathrm{H}_{3}\left(\mathrm{SiMe}_{3}\right)_{2}\right] \mathrm{K}(0.091 \mathrm{~g}, 0.41 \mathrm{mmol}, 1.0$ equiv $)$. 3-Nd was isolated as a brown powder $(0.173 \mathrm{~g}, 52 \%)$. No satisfactory elemental analyses could be obtained.

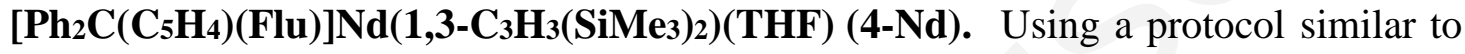
the one described above for 2-Y, 4-Nd was obtained from 4-H2 $(1.00 \mathrm{~g}, 2.5 \mathrm{mmol}), \mathrm{PhCH}_{2} \mathrm{~K}$ (0.69 g, 5.3 mmol, 2.1 equiv), $\mathrm{NdCl}_{3}(\mathrm{THF})_{2}(0.99 \mathrm{~g}, 2.5 \mathrm{mmol}, 1.0$ equiv) and [1,3$\left.\mathrm{C}_{3} \mathrm{H}_{3}\left(\mathrm{SiMe}_{3}\right)_{2}\right] \mathrm{K}(0.74 \mathrm{~g}, 3.3 \mathrm{mmol}, 1.3$ equiv $)$. 4-Nd was isolated as a deep red powder $(0.57$ g, 29\%). Single crystals of 4-Nd suitable for X-ray diffraction analysis were grown from an heptane solution at $-30{ }^{\circ} \mathrm{C}$. No satisfactory elemental analyses could be obtained.

$\left[\mathrm{Me}_{2} \mathrm{C}\left(\mathrm{C}_{5} \mathrm{H}_{4}\right)\left(3,6-t \mathrm{Bu}_{2} \mathrm{Flu}\right)\right] \mathrm{Nd}\left(1,3-\mathrm{C}_{3} \mathrm{H}_{3}\left(\mathrm{SiMe}_{3}\right)_{2}\right)(\mathrm{THF})$ (5-Nd). Using a protocol similar to that described above for $\mathbf{2}-\mathbf{Y}, \mathbf{5}-\mathbf{N d}$ was prepared from $\mathbf{5}-\mathbf{H}_{2}(0.80 \mathrm{~g}, 2.1 \mathrm{mmol})$, $\mathrm{PhCH}_{2} \mathrm{~K}\left(0.57 \mathrm{~g}, 4.4 \mathrm{mmol}, 2.1\right.$ equiv), $\mathrm{NdCl}_{3}(\mathrm{THF})_{2}(0.82 \mathrm{~g}, 2.1 \mathrm{mmol}, 1.0$ equiv) and [1,3$\left.\mathrm{C}_{3} \mathrm{H}_{3}\left(\mathrm{SiMe}_{3}\right)_{2}\right] \mathrm{K}(0.47 \mathrm{~g}, 2.1 \mathrm{mmol}, 1.0$ equiv). 5-Nd was isolated as a dark red powder $(0.60$ g, $37 \%$ ). No satisfactory elemental analyses could be obtained.

$\left[\mathrm{Me}_{2} \mathrm{C}\left(\mathrm{C}_{5} \mathrm{H}_{4}\right)(2,7-d i c u m y l F l u)\right] N d\left(1,3-\mathrm{C}_{3} \mathrm{H}_{3}\left(\mathrm{SiMe}_{2}\right)\right.$ )(THF) $\quad$ (6-Nd). Using a protocol similar to that described above for $\mathbf{2 - Y}$, 6-Nd was prepared from $\mathbf{6}-\mathbf{H}_{2}(0.55 \mathrm{~g}, 1.1$ mmol), $\mathrm{PhCH}_{2} \mathrm{~K}$ (0.30 g, $2.3 \mathrm{mmol}, 2.1$ equiv), $\mathrm{NdCl}_{3}(\mathrm{THF})_{2}(0.43 \mathrm{~g}, 1.1 \mathrm{mmol}, 1.0$ equiv) and $\left[1,3-\mathrm{C}_{3} \mathrm{H}_{3}\left(\mathrm{SiMe}_{3}\right)_{2}\right] \mathrm{K}(0.24 \mathrm{~g}, 1.1 \mathrm{mmol}, 1.0$ equiv $)$. 6-Nd was isolated as a brown powder $(0.74 \mathrm{~g}, 75 \%)$. No satisfactory elemental analyses could be obtained. 
$\left[\mathrm{Me}_{2} \mathrm{C}\left(\mathrm{C}_{5} \mathrm{H}_{4}\right)\left(3,6-t \mathrm{Bu}_{2} \mathrm{Flu}\right)\right] \mathrm{Nd}\left(1,3-\mathrm{C}_{3} \mathrm{H}_{3}\left(\mathrm{SiMe}_{3}\right)_{2}\right)(\mathrm{THF})(7-\mathrm{Nd})$. Using a protocol similar to that described above for 2-Y, 7-Nd was prepared from 7-H2 $(0.50 \mathrm{~g}, 0.79 \mathrm{mmol})$, $\mathrm{PhCH}_{2} \mathrm{~K}\left(0.22 \mathrm{~g}, 1.7 \mathrm{mmol}, 2.1\right.$ equiv), $\mathrm{NdCl}_{3}(\mathrm{THF})_{2}(0.31 \mathrm{~g}, 0.79 \mathrm{mmol}, 1.0$ equiv) and [1,3$\left.\mathrm{C}_{3} \mathrm{H}_{3}\left(\mathrm{SiMe}_{3}\right)_{2}\right] \mathrm{K}(0.18 \mathrm{~g}, 0.79 \mathrm{mmol}, 1.0$ equiv $)$. 7-Nd was isolated as a brown powder $(0.68$ g, 83\%). No satisfactory elemental analyses could be obtained.

$\left[\mathrm{Me}_{2} \mathrm{C}\left(\mathrm{C}_{5} \mathrm{H}_{4}\right)\left(2,7-t \mathrm{Bu}_{2} \mathrm{Flu}\right)\right] \mathrm{Sc}\left(1,3-\mathrm{C}_{3} \mathrm{H}_{3}\left(\mathrm{SiMe}_{3}\right)_{2}\right)$ (2-Sc). Using a protocol similar to that described above for 2-Y, 2-Sc was prepared from $\mathbf{2}-\mathbf{H}_{2}(0.30 \mathrm{~g}, 0.78 \mathrm{mmol}), \mathrm{PhCH}_{2} \mathrm{~K}$ (0.21 g, $1.6 \mathrm{mmol}, 2.1$ equiv), $\mathrm{ScCl}_{3}(\mathrm{THF})_{3}(0.29 \mathrm{~g}, 0.78 \mathrm{mmol}, 1.0$ equiv) and [1,3$\left.\mathrm{C}_{3} \mathrm{H}_{3}\left(\mathrm{SiMe}_{3}\right)_{2}\right] \mathrm{K}(0.18 \mathrm{~g}, 0.78 \mathrm{mmol}, 1.0$ equiv). 2-Sc was isolated as a bright red powder $(0.35 \mathrm{~g}, 72 \%) .{ }^{1} \mathrm{H}$ NMR $\left(\mathrm{C}_{6} \mathrm{D}_{6}, 500 \mathrm{MHz}, 25{ }^{\circ} \mathrm{C}\right): \delta 7.96\left(\mathrm{br} \mathrm{d}, J_{\mathrm{H}-\mathrm{H}}=8.6,2 \mathrm{H}, \mathrm{Flu}\right), 7.83(\mathrm{~s}$, 2H, Flu $), 7.38\left(\mathrm{t}, J_{\mathrm{H}-\mathrm{H}}=16.2,1 \mathrm{H},\left(\mathrm{Me}_{3} \mathrm{Si}\right) \mathrm{CHCHCH}\left(\mathrm{SiMe}_{3}\right)\right), 7.15(2 \mathrm{H}$, Flu, overlapped with the signal from $\left.\mathrm{C}_{6} \mathrm{D}_{6}\right), 6.56\left(\mathrm{t}, J_{\mathrm{H}-\mathrm{H}}=2.6,2 \mathrm{H}, \mathrm{Cp}\right), 5.26\left(\mathrm{t}, J_{\mathrm{H}-\mathrm{H}}=2.7,2 \mathrm{H}, \mathrm{Cp}\right), 2.85\left(\mathrm{~d}, J_{\mathrm{H}-\mathrm{H}}\right.$ $\left.=16.1,2 \mathrm{H},(\mathrm{Me} 3 \mathrm{Si}) \mathrm{CHCHCH}\left(\mathrm{SiMe}_{3}\right)\right), 2.32\left(\mathrm{~s}, 6 \mathrm{H},\left(\mathrm{CH}_{3}\right)_{2} \mathrm{C}-\right), 1.32(\mathrm{~s}, 18 \mathrm{H}, t \mathrm{Bu}),-0.13(\mathrm{~s}$, 18H, SiMe $).{ }^{13} \mathrm{C}\left\{{ }^{1} \mathrm{H}\right\}$ NMR $\left(\mathrm{C}_{6} \mathrm{D}_{6}, 125 \mathrm{MHz}, 25{ }^{\circ} \mathrm{C}\right): \delta 166.4\left(\left(\mathrm{Me}_{3} \mathrm{Si}\right) \mathrm{CHCHCH}\left(\mathrm{SiMe}_{3}\right)\right)$, 149.6 (quat.C, $t \mathrm{Bu}-C(\mathrm{Flu})$ ), 126.9 (quat.C, Flu), 125.6 (quat.C, $\mathrm{Cp}$ ), $123.7(C \mathrm{H}, \mathrm{Flu}), 121.3$ (quat.C, Flu), 120.0 (CH, Flu), 118.3 (C-1 and C-8, Flu), 113.7 (Cp), 105.6 (Cp), 92.1 (C-9, Flu), 88.4 (( $\left.\mathrm{Me}_{3} \mathrm{Si}\right) \mathrm{CHCHCH}\left(\mathrm{SiMe}_{3}\right)$ ), 42.5 (quat.C, $\left(\mathrm{CH}_{3}\right)_{2} \mathrm{C}$-), 36.0 (quat.C, $\left(\mathrm{CH}_{3}\right)_{3} C$-Flu), $\left.32.1\left(\left(\mathrm{CH}_{3}\right)_{3} \mathrm{C}-\mathrm{Flu}\right)\right), 30.2\left(\left(\mathrm{CH}_{3}\right)_{2} \mathrm{C}\right), 1.6\left(\mathrm{Si}_{3}\right)$. No satisfactory elemental analyses could be obtained, even on recrystallized material.

$\left[\mathrm{Me}_{2} \mathrm{C}\left(\mathrm{C}_{5} \mathrm{H}_{4}\right)\left(2,7-t \mathrm{Bu}_{2} \mathrm{Flu}\right)\right] \mathrm{La}\left(1,3-\mathrm{C}_{3} \mathrm{H}_{3}\left(\mathrm{SiMe}_{3}\right)_{2}\right)(\mathrm{THF}) \quad$ (2-La). Pro-ligand 2-H (0.50 g, $1.3 \mathrm{mmol})$ and $\mathrm{PhCH}_{2} \mathrm{~K}(0.36 \mathrm{~g}, 2.7 \mathrm{mmol}, 2.1$ equiv) in THF (30 mL) were stirred overnight at $50{ }^{\circ} \mathrm{C}$. The solution turned red. In parallel, anhydrous $\mathrm{LaCl}_{3}(0.32 \mathrm{~g}, 1.3 \mathrm{mmol}$, 1.0 equiv) was stirred in THF $(30 \mathrm{~mL})$ for 4 days at $50{ }^{\circ} \mathrm{C}$. Volatiles were removed under vacuum in both Schlenk flasks and the di-anionic ligand was added to the THF-adduct of $\mathrm{LaCl}_{3}$. To this mixture of solids was added $\left[1,3-\mathrm{C}_{3} \mathrm{H}_{3}\left(\mathrm{SiMe}_{3}\right)_{2}\right] \mathrm{K}(0.29 \mathrm{~g}, 1.3 \mathrm{mmol}, 1.0$ 
equiv) in $\mathrm{Et}_{2} \mathrm{O}(40 \mathrm{~mL})$. The mixture was stirred for 3 days at $30{ }^{\circ} \mathrm{C}$. The resulting orange solution was decanted and filtered to remove insoluble materials. Volatiles were removed under vacuum to give 2-La as a crystalline yellow powder $(0.79 \mathrm{~g}, 78 \%) .{ }^{1} \mathrm{H}$ NMR $\left(\mathrm{C}_{6} \mathrm{D}_{6}\right.$, $\left.500 \mathrm{MHz}, 25{ }^{\circ} \mathrm{C}\right): \delta 8.21\left(\right.$ br d, $\left.J_{\mathrm{H}-\mathrm{H}}=8.6,2 \mathrm{H}, \mathrm{Flu}\right), 8.15$ (br s, 2H, Flu), 7.16 (Flu, overlapped with the signal from $\left.\mathrm{C}_{6} \mathrm{D}_{6}, 2 \mathrm{H}\right), 6.26$ (br s, $\left.2 \mathrm{H}, \mathrm{Cp}\right), 6.21\left(\mathrm{t}, J_{\mathrm{H}-\mathrm{H}}=16.4,1 \mathrm{H}\right.$, ( $\left.\mathrm{Me}_{3} \mathrm{Si}\right) \mathrm{CHCHCH}\left(\mathrm{SiMe}_{3}\right)$ ), 5.92 (br s, 2H, Cp), 3.04 (br s, 4H, coord. THF), 2.46 (s, 6H, $\left.\left(\mathrm{CH}_{3}\right)_{2} \mathrm{C}\right), 1.42\left(\mathrm{~s}, 18 \mathrm{H}+2 \mathrm{H}, t \mathrm{Bu}\right.$ and $\left(\mathrm{Me}_{3} \mathrm{Si}\right) \mathrm{CHCHCH}\left(\mathrm{SiMe}_{3}\right)$ overlapped), 1.14 (br s, 4H, coord. THF), 0.12 (s, 18H, $\left.\left(M e_{3} \mathrm{Si}\right) \mathrm{CHCHCH}(\mathrm{SiMe})\right)$. ${ }^{13} \mathrm{C}\left\{{ }^{1} \mathrm{H}\right\} \mathrm{NMR}\left(\mathrm{C}_{6} \mathrm{D}_{6}, 125 \mathrm{MHz}, 25\right.$ $\left.{ }^{\circ} \mathrm{C}\right): \delta 157.8\left(\left(\mathrm{Me}_{3} \mathrm{Si}\right) \mathrm{CHCHCH}\left(\mathrm{SiMe}_{3}\right)\right), 148.5$ (quat.C, $\left.t \mathrm{Bu}-C(\mathrm{Flu})\right), 133.8$ (quat.C, $\mathrm{Cp}$ ), 131.4 (quat.C, Flu), 123.1 (CH, Flu), 119.3 (quat.C, Flu), $117.1(\mathrm{CH}, \mathrm{Flu}), 115.3(\mathrm{C}-1$ and C8, Flu), 111.9 (Cp), 104.2 (Cp), 99.0 (C-9, Flu), 69.9 (coord. THF), 41.0 (quat.C, $\left(\mathrm{CH}_{3}\right)_{2} \mathrm{C}$-), 36.1 (quat.C, $\left(\mathrm{CH}_{3}\right)_{3} \mathrm{C}$-Flu $), 32.4\left(\left(\mathrm{CH}_{3}\right)_{3} \mathrm{C}-\mathrm{Flu}\right), 31.3\left(\left(\mathrm{CH}_{3}\right)_{2} \mathrm{C}-\right), 1.7$ (SiMe $)$. Single crystals of 2-La suitable for X-ray diffraction analysis were grown from an heptane solution at -30 ${ }^{\circ} \mathrm{C}$. Anal. Calcd for $\mathrm{C}_{42} \mathrm{H}_{63} \mathrm{Si}_{2} \mathrm{LaO}$ (779.04): C, 64.75; H, 8.15. No satisfactory elemental analyses could be obtained, even on recrystallized material; typical results returned low $\mathrm{C}$ contents (Found: C, 60.39; H, 8.57).

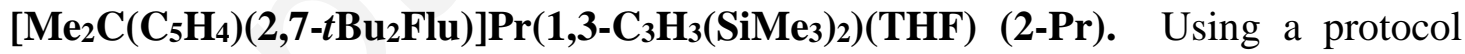
similar to that described above for 2-La, 2-Pr was prepared from 2-H2 $(0.70 \mathrm{~g}, 1.8 \mathrm{mmol})$, $\mathrm{PhCH}_{2} \mathrm{~K}\left(0.50 \mathrm{~g}, 3.8 \mathrm{mmol}, 2.1\right.$ equiv) in THF (20 mL), $\mathrm{PrCl}_{3}(0.45 \mathrm{~g}, 1.8 \mathrm{mmol}, 1.0$ equiv) and $\left[1,3-\mathrm{C}_{3} \mathrm{H}_{3}\left(\mathrm{SiMe}_{3}\right)_{2}\right] \mathrm{K}(0.41 \mathrm{~g}, 1.8 \mathrm{mmol}, 1.0$ equiv $)$. 2-Pr was isolated as a crystalline orange powder $(1.2 \mathrm{~g}, 84 \%)$. Single crystals of 2-Pr suitable for X-ray diffraction analysis were grown from an heptane solution at $-30{ }^{\circ} \mathrm{C}$. No satisfactory elemental analyses could be obtained, even on recrystallized material.

$\left[\mathrm{Me}_{2} \mathrm{C}\left(\mathrm{C}_{5} \mathrm{H}_{4}\right)\left(2,7-t \mathrm{Bu}_{2} \mathrm{Flu}\right)\right] \mathrm{Sm}\left(1,3-\mathrm{C}_{3} \mathrm{H}_{3}\left(\mathrm{SiMe}_{3}\right)_{2}\right)(\mathrm{THF})$ (2-Sm). Using a protocol similar to that described above for 2-La, 2-Sm was prepared from 2-H2 $(0.60 \mathrm{~g}, 1.6 \mathrm{mmol})$, 
$\mathrm{PhCH}_{2} \mathrm{~K}\left(0.43 \mathrm{~g}, 3.3 \mathrm{mmol}, 2.1\right.$ equiv) in THF (30 mL), $\mathrm{SmCl}_{3}(0.40 \mathrm{~g}, 1.6 \mathrm{mmol}, 1.0$ equiv) and $\left[1,3-\mathrm{C}_{3} \mathrm{H}_{3}\left(\mathrm{SiMe}_{3}\right)_{2}\right] \mathrm{K}(0.35 \mathrm{~g}, 1.6 \mathrm{mmol}, 1.0$ equiv $)$. 2-Sm was isolated as a brownish grey crystalline powder $(0.72 \mathrm{~g}, 58 \%)$. Single crystals of 2-Sm suitable for X-ray diffraction analysis were grown from an heptane solution at $-30{ }^{\circ} \mathrm{C}$. Anal. Calcd for $\mathrm{C}_{42} \mathrm{H}_{63} \mathrm{Si}_{2} \mathrm{SmO}$ (790.50): C, 63.82; H, 8.03. No satisfactory elemental analyses could be obtained, even on recrystallized material; typical results returned low $\mathrm{C}$ contents (Found: $\mathrm{C}, 59.79 ; \mathrm{H}, 7.56$ ).

Typical procedure for styrene polymerization. In a typical experiment (Table 2, entry 2), the pre-catalyst $(c a .8 \mathrm{mg})$, cyclohexane $(2.7 \mathrm{~mL})$ and a solution of $(n \mathrm{Bu})_{2} \mathrm{Mg}(0.1$ $\mathrm{mL}$ of a $1.0 \mathrm{M}$ solution in heptane) were introduced in the glovebox in a Schlenk flask. The tube was capped with a septum. Out of the glovebox, the tube was heated with an oil bath at $60{ }^{\circ} \mathrm{C}$. Under vigorous stirring, styrene $(2.7 \mathrm{~mL})$ was added with a syringe. When the desired polymerization time was reached, methanol $(10 \mathrm{~mL})$ was added to quench the reaction. The precipitated polymer was washed with methanol (ca. $10 \mathrm{~mL}$ ), filtered and dried under vacuum overnight at $50{ }^{\circ} \mathrm{C}$.

Crystal Structure Determination of 1-Nd-K(allyl), 2-La, 2-Pr, 2-Nd, 2-Sm and 4Nd. Single crystals of 1-Nd-K(allyl) suitable for X-ray diffraction analysis were grown from a toluene solution at room temperature. Single crystals of 2-La, 2-Pr, 2-Nd, 2-Sm and 4-Nd were grown from heptane solutions at $-30{ }^{\circ} \mathrm{C}$. Diffraction data were collected at $150 \mathrm{~K}$ using a Bruker APEX CCD diffractometer with graphite-monochromated MoKa radiation $(1=$ $0.71073 \AA$ Á). A combination of $\omega$ - and $\varphi$-scans was carried out to obtain at least a unique data set. The crystal structures were solved by direct methods, remaining atoms were located from difference Fourier synthesis followed by full-matrix least-squares refinement based on $\mathrm{F}^{2}$ (programs SIR97 and SHELXL-97). Carbon- and oxygen-bound hydrogen atoms were placed at calculated positions and forced to ride on the attached atom. All non-hydrogen atoms were refined with anisotropic displacement parameters. The locations of the largest 
peaks in the final difference Fourier map calculation as well as the magnitude of the residual electron densities were of no chemical significance. Main crystal and refinement data are summarized in Table S1.

Computational Details. The calculations were carried out with the Gaussian 09 program. $^{54}$ Density Functional Theory (DFT) with the hybrid functional B3PW91 ${ }^{55,56}$ was used to perform calculations. Neodymium was represented with a large-core StuttgartDresden relativistic effective core potential (RECP) that includes the $4 f$ electrons in core associated with its adapted basis set. ${ }^{57}$ This basis set was augmented by a set of $f$ polarization functions $(\alpha=1.000)$. The large-core RECP was chosen according to the formal oxidation state of the lanthanide. The Stuttgart-Dresden relativistic effective core potential was employed for Si atoms in combination with its optimized basis set to which was added a d polarization function $(\alpha=0.284){ }^{58,59}$ All other atoms were described with a $6-31+\mathrm{G}(\mathrm{d}, \mathrm{p})$ double $-\zeta$ quality basis set. The SMD solvation model was used to evaluate solvation energies by a self-consistent reaction field (SCRF) approach based on accurate numerical solutions of the Poisson-Boltzmann equation. ${ }^{60}$ Toluene was chosen as solvent. Electronic energies and enthalpies were calculated at $T=298 \mathrm{~K}$. Activation barriers $\Delta H^{\#}$ are defined in the same way as in the approach used by Castro et $a l .{ }^{44}$ (see Figure 9). Geometry optimizations were carried out without any symmetry constraints and the nature of the extrema was verified by analytical frequency calculations. Intrinsic Reaction Coordinates (IRC) calculations were performed to determine connectivity of the optimized transition states. NBO analysis ${ }^{61}$ of the neodymium system has been done by applying Clark et al. method. ${ }^{62}$ The Natural Population Analysis (NPA) ${ }^{61}$ was used to obtain the electronic charges. 

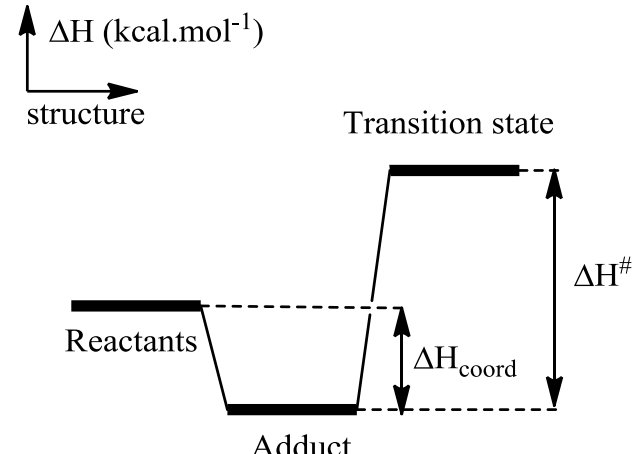

Adduct

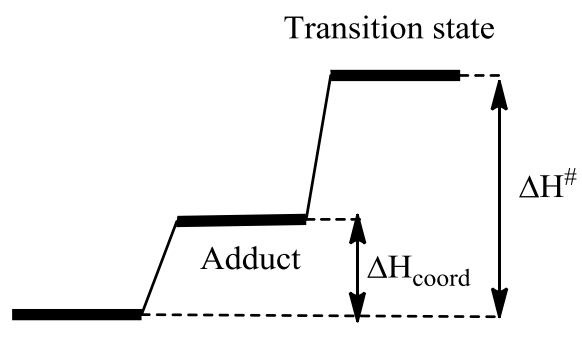

Reactants

Figure 9. Definition of $\Delta H^{\#}$ depending on the sign of $\Delta H_{\text {coord. }}{ }^{44}$

Acknowledgements. This work was gratefully supported by Total and Total Research and Technology Feluy (PhD grants to EL and EL).

Supporting Information Available. X-ray (including cif files) and NMR data for complexes; representative NMR, GPC and DSC data for polymers; Cartesian coordinates and energy optimized stationary points.

The authors declare no conflict of interest.

\section{References and Notes}

1 Ishihara, N.; Seimiya, T.; Kuramoto, M.; Uoi, M. Crystalline syndiotactic polystyrene. Macromolecules 1986, 19, 2464-2465.

2 Ishihara, N.; Kuramoto, M.; Uoi, M. Stereospecific polymerization of styrene giving the syndiotactic polymer. Macromolecules 1988, 21, 3356-3360.

3 Zambelli, A.; Oliva, L.; Pellecchia, C. Soluble catalysts for syndiotactic polymerization of styrene. Macromolecules 1989, 22, 2129-2130.

4 Kaminsky, W.; Lenk, S.; Scholz, V.; Roesky, H. W.; Herzog, A. Fluorinated halfsandwich complexes as catalysts in syndiospecific styrene polymerization. Macromolecules 1997, 30, 7647-7650. 
5 Schneider, N.; Prosenc, M.-H.; Brintzinger, H.-H. Cyclopenta[1]phenanthrene titanium trichloride derivatives: syntheses, crystal structure and properties as catalysts for styrene polymerization. J. Organomet. Chem. 1997, 545-546, 291-295.

6 Ready, T. E.; Chien, J. C. W.; Rausch, M. D. Alkyl-substituted indenyl titanium precursors for syndiospecific Ziegler-Natta polymerization of styrene. J. Organomet. Chem. 1996, 519, 21-28.

7 Okuda, J.; Masoud, E. Syndiospecific polymerization of styrene using methylaluminoxane-activated bis(phenolato)titanium complexes. Macromol. Chem. Phys. 1998, 199, 543-545.

8 Kirillov, E.; Lehmann, C. W.; Razavi, A.; Carpentier, J.-F. Highly syndiospecific polymerization of styrene catalyzed by allyl lanthanide complexes. J. Am. Chem. Soc. 2004, 126, 12240-12241.

9 Rodrigues, A.-S.; Kirillov, E.; Lehmann, C. W.; Roisnel, T.; Vuillemin, B.; Razavi, A.; Carpentier, J.-F. Allyl ansa-lanthanidocenes: single-component, single-site catalysts for controlled syndiospecific styrene and styrene-ethylene (co)polymerization. Chem.-Eur. $J$. 2007, $13,5548-5565$.

10 Perrin, L.; Kirillov, E.; Carpentier, J.-F.; Maron, L. DFT Investigation of the tacticity control during styrene polymerization catalyzed by single-component allyl ansalanthanidocenes $\left\{\left(\mathrm{C}_{5} \mathrm{H}_{4} \mathrm{CMe}_{2}\left(9-\mathrm{C}_{13} \mathrm{H}_{8}\right)\right\} \mathrm{Ln}\left(\mathrm{C}_{3} \mathrm{H}_{5}\right)\right.$. Macromolecules 2010, 43, 63306336.

11 Perrin, L.; Sarazin, Y.; Kirillov, E.; Carpentier, J.-F.; Maron, L. On the initiation mechanism of syndiospecific styrene polymerization catalyzed by single-component ansa-lanthanidocenes. Chem. -Eur. J. 2009, 15, 3773-3783.

12 Luo, Y.; Baldamus, J.; Hou, Z. Scandium half-metallocene-catalyzed syndiospecific styrene polymerization and styrene-ethylene copolymerization: unprecedented incorporation of syndiotactic styrene-styrene sequences in styrene-ethylene copolymers. J. Am. Chem. Soc. 2004, 126, 13910-13911.

13 Cui, L.; Ba, X.; Teng, H.; Ying, L.; Li, K.; Jin, Y. Preliminary investigations on polymerization catalysts composed of lanthanocene and methylaluminoxane. Polym. Bull. 1998, 40, 729-734. 
14 Baudry-Barbier, D.; Camus, E.; Dormond, A.; Visseaux, M. Homogeneous organolanthanide catalysts for the selective polymerization of styrene without aluminium cocatalysts. Appl. Organomet. Chem. 1999, 13, 813-817.

15 Harder, S. The chemistry of $\mathrm{Ca}^{\mathrm{II}}$ and $\mathrm{Yb}^{\mathrm{II}}$ : astoundingly similar but not equal! Angew. Chem., Int. Ed. 2004, 43, 2714-2718.

16 Trifonov, A. A.; Skvortsov, G. G.; Lyubov, D. M.; Skorodumova, N. A.; Fukin, G. K.; Baranov, E. V; Glushakova, V. N. Postmetallocene lanthanide-hydrido chemistry: a new family of complexes $\left[\left\{\operatorname{Ln}\left\{(\mathrm{Me} 3 \mathrm{Si})_{2} \mathrm{NC}(\mathrm{NiPr})_{2}\right\}_{2}(\mu-\mathrm{H})\right\}_{2}\right](\mathrm{Ln}=\mathrm{Y}, \mathrm{Nd}, \mathrm{Sm}, \mathrm{Gd}, \mathrm{Yb})$ supported by guanidinate ligands-synthesis, structure, and catalytic activity in olefin polymerization.. Chem. -Eur. J. 2006, 12, 5320-5327.

17 Pan, Y.; Rong, W.; Jian, Z.; Cui, D. Ligands dominate highly syndioselective polymerization of styrene by using constrained-geometry-configuration rare-earth metal precursors. Macromolecules 2012, 45, 1248-1253.

18 Jaroschik, F.; Shima, T.; Li, X.; Mori, K.; Ricard, L.; Le Goff, X.-F.; Nief, F.; Hou, Z. Synthesis, characterization, and reactivity of mono(phospholyl)lanthanoid(III) bis(dimethylaminobenzyl) complexes. Organometallics 2007, 26, 5654-5660.

19 Luo, Y.; Nishiura, M.; Hou, Z. Rare earth metal bis(alkyl) complexes bearing a monodentate arylamido ancillary ligand: synthesis, structure, and olefin polymerization catalysis. J. Organomet. Chem. 2007, 692, 536-544.

Piesik, D. F.-J.; Häbe, K.; Harder, S. Ca-mediated styrene polymerization: tacticity control by ligand design. Eur. J. Inorg. Chem. 2007, 2007, 5652-5661.

21 Nishiura, M.; Mashiko, T.; Hou, Z. Synthesis and styrene polymerisation catalysis of $\eta^{5}$ and $\eta^{1}$-pyrrolyl-ligated cationic rare earth metal aminobenzyl complexes. Chem. Commun. 2008, 2019-2021.

22 Fang, X.; Li, X.; Hou, Z.; Assoud, J.; Zhao, R. 1,2-azaborolyl-ligated half-sandwich complexes of scandium(III) and lutetium(III): synthesis, structures, and syndiotactic polymerization of styrene. Organometallics 2009, 28, 517-522.

23 Jian, Z.; Tang, S.; Cui, D. A lutetium allyl complex that bears a pyridyl-functionalized cyclopentadienyl ligand: dual catalysis on highly syndiospecific and cis-1,4-selective (co)polymerizations of styrene and butadiene. Chem.-Eur. J. 2010, 16, 14007-14015. 
24 Liu, D.; Luo, Y.; Gao, W.; Cui, D. Stereoselective polymerization of styrene with cationic scandium precursors bearing quinolyl aniline ligands. Organometallics 2010, 29, $1916-1623$.

$25 \mathrm{Xu}, \mathrm{X}$; Chen, Y.; Feng, J.; Zou, G.; Sun, J. Half-sandwich indenyl rare earth metal dialkyl complexes: syntheses, structures, and catalytic activities of (1,3$\left.\left(\mathrm{SiMe}_{3}\right)_{2} \mathrm{C}_{9} \mathrm{H}_{5}\right) \mathrm{Ln}\left(\mathrm{CH}_{2} \mathrm{SiMe}_{3}\right)_{2}(\mathrm{THF})$. Organometallics 2010, 29, 549-553.

26 Jian, Z.; Cui, D.; Hou, Z. Rare-earth-metal-hydrocarbyl complexes bearing linked cyclopentadienyl or fluorenyl ligands: synthesis, catalyzed styrene polymerization, and structure-reactivity relationship. Chem.-Eur. J. 2012, 18, 2674-2684.

27 Lei, Y.; Wang, Y.; Luo, Y. Synthesis, characterization, and styrene polymerization catalysis of pyridyl-functionalized indenyl rare earth metal bis(silylamide) complexes. $J$. Organomet. Chem. 2013, 738, 24-28.

28 Li, X.; Wang, X.; Tong, X.; Zhang, H.; Chen, Y.; Liu, Y.; Liu, H.; Wang, X.; Nishiura, M.; He, H.; Lin, Z.; Zhang, S.; Hou, Z. Aluminum effects in the syndiospecific copolymerization of styrene with ethylene by cationic fluorenyl scandium alkyl catalysts. Organometallics 2013, 32, 1445-1458.

29 Luo, Y.; Chi, S.; Chen, J. Half-sandwich rare-earth-metal derivatives bearing pyrrolidinyl-functionalized cyclopentadienyl ligand: synthesis, characterization and catalysis in syndiospecific polymerization of styrene. New J. Chem. 2013, 37, $2675-2682$.

30 Chen, Y.; Wang, X.; Leng, X. Mono(boratabenzene) rare-earth metal dialkyl complexes: synthesis, structure and catalytic behaviors for styrene polymerization. Dalton Trans. 2015, 44, 5771-5776.

31 Malanga, M. Syndiotactic polystyrene materials. Adv. Mater. 2000, 12, 1869-1872.

32 Ewen, J. A.; Jones, R. L.; Razavi, A.; Ferrara, J. D. Syndiospecific propylene polymerizations with group 4 metallocenes. J. Am. Chem. Soc. 1988, 110, 6255-6256.

33 Irwin, L. J.; Zeits, P. D.; Reibenspies, J. H.; Miller, S. A. Diffuse diffraction from parallel/antiparallel metallocene pillars. Organometallics 2007, 26, 1129-1133.

34 Alt, H. G.; Zenk, R. Syndiospezifische polymerisation von propylen: 2- und 2,7substituierte metallocenkomplex des typs $\left(\mathrm{C}_{13} \mathrm{H}_{8}{ }_{n} \mathrm{R}_{\mathrm{n}} \mathrm{CR}_{2}{ }_{2} \mathrm{C}_{5} \mathrm{H}_{4}\right) \mathrm{MCl}_{2} \quad(\mathrm{n}=1,2 ; \mathrm{R}=$ alkoxy, alkyl, aryl, hal; $\mathrm{R}^{\prime}=\mathrm{Me}, \mathrm{Ph} ; \mathrm{M}=\mathrm{Zr}$, Hf). J. Organomet. Chem. 1996, 522, $39-54$. 
35 Effective ionic radii for 8-coordinate metal centers: $\mathrm{La}^{3+}, 1.16 \AA$; $\mathrm{Pr}^{3+}, 1.126 \AA$; $\mathrm{Nd}^{3+}$, $1.109 \AA ; \mathrm{Sm}^{3+}, 1.079 \AA$; see: Shannon, R. D. Revised effective ionic radii and systematic studies of interatomic distances in halides and chalcogenides. Acta Crystallogr. Sect. A 1976, 32, 751-767.

36 Rodrigues, A.-S.; Kirillov, E.; Lehmann, C. W.; Roisnel, T.; Vuillemin, B.; Razavi, A.; Carpentier, J.-F. Allyl ansa-lanthanidocenes: single-component, single-site catalysts for controlled syndiospecific styrene and styrene-ethylene (co)polymerization. Chem.-Eur. J. 2007, 13, 5548-5565.

37 Friebe, L.; Nuyken, O.; Obrecht, W. Neodymium-based Ziegler/Natta catalysts and their application in diene polymerization. Adv. Polym. Sci. 2006, 204, 1-154.

38 Terrier, M.; Visseaux, M.; Chenal, T.; Mortreux, A. Controlled trans-stereospecific polymerization of isoprene with lanthanide(III) borohydride/dialkylmagnesium systems: the improvement of the activity and selectivity, kinetic studies, and mechanistic aspects. J. Polym. Sci. A Polym. Chem. 2007, 45, 2400-2409.

39 Ajellal, N.; Furlan, L.; Thomas, C. M.; Casagrande, O. L.; Carpentier, J. F. Mixed aluminum-magnesium-rare earth allyl catalysts for controlled isoprene polymerization: modulation of stereocontrol. Macromol. Rapid Commun. 2006, 27, 338-343.

40 Fischbach, A.; Perdih, F.; Herdtweck, E.; Anwander, R. Structure-reactivity relationships in rare-earth metal carboxylate-based binary Ziegler-type catalysts. Organometallics 2006, 25, 1626-1642.

41 Sarazin, Y.; de Frémont, P.; Annunziata, L.; Duc, M.; Carpentier, J.-F. Syndio- and isoselective coordinative chain transfer polymerization of styrene promoted by ansalanthanidocene/dialkylmagnesium systems. Adv. Synth. Cat. 2011, 353, 1367-1374.

42 Rodrigues, A.-S.; Kirillov, E.; Vuillemin, B.; Razavi, A.; Carpentier, J.-F. Binary ansalanthanidocenes/dialkylmagnesium systems versus single-component catalyst: controlled synthesis of end-capped syndiotactic oligostyrenes. J. Mol. Catal. A Chem. 2007, 273, 87-91.

43 See the following reference and references cited therein: Bogaert, S.; Carpentier, J.-F.; Chenal, T.; Mortreux, A.; Ricart, G. Chlorolanthanocene-dialkylmagnesium systems for styrene bulk polymerization and styrene-ethylene block copolymerization. Macromol. Chem. Phys. 2000, 201, 1813-1822.

44 Castro, L.; Kirillov, E.; Miserque, O.; Welle, A.; Haspeslagh, L.; Carpentier, J.-F.; Maron, L. Are solvent and dispersion effects crucial in olefin polymerization DFT 
calculations? Some insights from propylene coordination and insertion reactions with group 3 and 4 metallocenes. ACS Catal. 2015, 5, 416-425.

45 Topographic steric maps were probed to describe catalytic pockets of 1-Nd, 2-Nd and 5Nd. (see Figure S38). The steric effect has only a little impact on the computed map, as for the three catalysts the percent buried volume (\%Vbur) shows no significant difference, see: Falivene, L.; Credendino, R.; Poater, A.; Petta, A.; Serra, L.; Oliva, R.; Scarano, V.; Cavallo, L. SambVca 2. A web tool for analyzing catalytic pockets with topographic steric maps. Organometallics 2016, 35, 2286-2293).

46 Schultz, N. E.; Zhao, Y.; Truhlar, D. G. Benchmarking approximate density functional theory for s/d excitation energies in $3 \mathrm{~d}$ transition, metal cations. J. Comput. Chem. 2008, $29,185-189$.

47 Zhao, Y.; Truhlar, D. G. Density functionals with broad applicability in chemistry. Acc. Chem. Res. 2008, 41, 157-167.

48 Alt, H. G.; Samuel, E. Fluorenyl complexes of zirconium and hafnium as catalysts for olefin polymerization. Chem. Soc. Rev. 1998, 27, 323-329.

49 Coşkun, N.; Erden, I. An efficient method for fulvene synthesis. Tetrahedron 2011, 67, 8607-8614.

50 Razavi, A.; Ferrara, J. Preparation and crystal structures of the complexes $\left(\eta^{5}-\mathrm{C}_{5} \mathrm{H}_{4} \mathrm{CMe}_{2}-\right.$ $\left.\eta^{5}-\mathrm{C}_{13} \mathrm{H}_{8}\right) \mathrm{MCl}_{2}(\mathrm{M}=\mathrm{Zr}$, Hf $)$ and their role in the catalytic formation of syndiotactic polypropylene. J. Organomet. Chem. 1992, 435, 299-310.

51 Razavi, A. (Fina Research) WO Pat. Appl. 2000049029, Aug 24, 2000

52 Jeske, G.; Lauke, H.; Mauermann,H.; Swepston, P. N.; Schumann, H.; Marks, T. J. Highly reactive organolanthanides. Systematic routes to and olefin chemistry of early and late bis(pentamethylcyclopentadienyl) $4 \mathrm{f}$ hydrocarbyl and hydride complexes. J. Am. Chem. Soc. 1985, 107, 8091-8103.

53 Jeske, G.; Schock, L. E.; Swepston, P. N.; Schumann, H.; Marks, T. J. Highly reactive organolanthanides. Synthesis, chemistry, and structures of $4 \mathrm{f}$ hydrocarbyls and hydrides with chelating bis(polymethylcyclopentadienyl) ligands. J. Am. Chem. Soc. 1985, 107, 8103-8110.

54 Gaussian 09 Revision D.01; Frisch, M. J.; Trucks, G. W.; Schlegel, H. B.; Scuseria, G. E.; Robb, M. A.; Cheeseman, J. R.; Scalmani, G.; Barone, V.; Mennucci, B.; Petersson, G. A.; others. Gaussian Inc Wallingford CT 2009. 
55 Becke, A. D. Density- functional thermochemistry. III. The role of exact exchange. J. Chem. Phys. 1993, 98, 5648-5652.

56 Burke, K.; Perdew, J. P.; Wang, Y. In Electronic Density Functional Theory: Recent Progress and New Directions; Dobson, J. F., Vignale, G., Das, M. P., Eds.; Plenum: New York, 1998.

57 Dolg, M.; Stoll, H.; Savin, A.; Preuss, H. Energy-adjusted pseudopotentials for the rare earth elements. Theor. Chem. Acc. Theory Comput. Model. Theor. Chim. Acta 1989, 75, 173-194.

58 Bergner, A.; Dolg, M.; Küchle, W.; Stoll, H.; Preuss, H. Ab initio energy-adjusted pseudopotentials for elements of groups 13-17. Mol. Phys. 1993, 80, 1431-1441.

59 Höllwarth, A.; Böhme, M.; Dapprich, S.; Ehlers, A. W.; Gobbi, A.; Jonas, V.; Köhler, K. F.; Stegmann, R.; Veldkamp, A.; Frenking, G. A set of d-polarization functions for pseudo-potential basis sets of the main group elements $\mathrm{Al}-\mathrm{Bi}$ and f-type polarization functions for Zn, Cd, Hg. Chem. Phys. Lett. 1993, 208, 237-240.

60 Marenich, A. V.; Cramer, C. J.; Truhlar, D. G. Universal solvation model based on solute electron density and on a continuum model of the solvent defined by the bulk dielectric constant and atomic surface tensions. J. Phys. Chem. B 2009, 113, 6378-6396.

61 Reed, A. E.; Curtiss, L. A.; Weinhold, F. Intermolecular interactions from a natural bond orbital, donor-acceptor viewpoint. Chem. Rev. 1988, 88, 899-926.

62 Clark, D. L.; Gordon, J. C.; Hay, P. J.; Martin, R. L.; Poli, R. DFT study of tris(bis(trimethylsilyl)methyl)lanthanum and samarium. Organometallics 2002, 21, 50005006. 